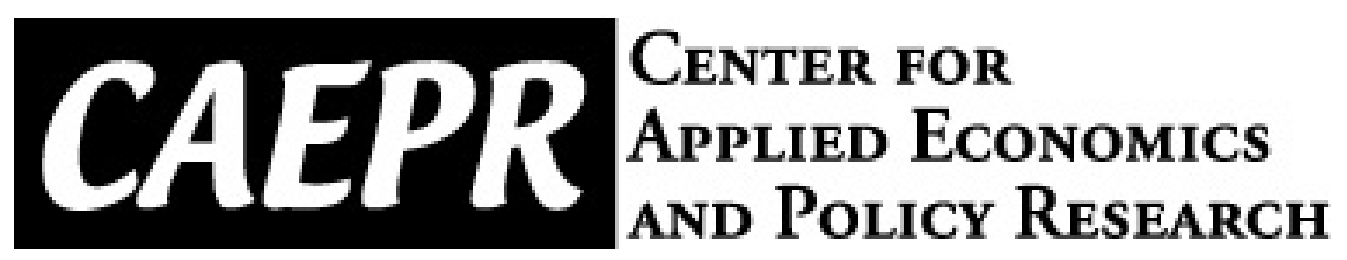

CAEPR Working Paper

\#2008-024

\title{
Demographic Uncertainty and Welfare in a Life-cycle Model under Alternative Public Pension Systems
}

\author{
M Saifur Rahman \\ Indiana University Bloomington
}

September 19, 2008

This paper can be downloaded without charge from the Social Science Research Network electronic library at: http://ssrn.com/abstract=1270643.

The Center for Applied Economics and Policy Research resides in the Department of Economics at Indiana University Bloomington. CAEPR can be found on the Internet at: http://www.indiana.edu/ caepr. CAEPR can be reached via email at caepr@indiana.edu or via phone at 812-855-4050.

@2008 by M Saifur Rahman. All rights reserved. Short sections of text, not to exceed two paragraphs, may be quoted without explicit permission provided that full credit, including ${ }^{\circ}$ notice, is given to the source. 


\title{
Demographic Uncertainty and Welfare in a Life-cycle Model under Alternative Public Pension Systems
}

\author{
M Saifur Rahman* \\ Indiana University at Bloomington \\ Email: murahman@indiana.edu
}

September 8, 2008

\begin{abstract}
In this paper, I analyze consumption, aggregate savings,output and welfare implications of five different social security arragements whenever there is demographic uncertanity. Following Bohn(2002), I analyze the effect of an uncetain population growth in an extended version of a modified Life-cycle model developed by Gertler(1999). Population growth dampens savings and output under all arrangements. Pay-as-you-go-Defined Benefit system appears to fare better than all other alternatives, falling short of the private annuity market with no pension system. But social security in general increases social welfare, with Fully Funded systems faring the best. Thus there appears to be a clear tradeoff bewteen growth and social welfare. The social security system also reduces the volatility of the economy.
\end{abstract}

JEL Classification: E21, E62, E64, H23, H24, H41, H55, J18, J26

Keywords: Demographic uncertainty, Social welfare, Life-cycle model, Annuity market, Pay-as-you-go, Fully funded, Defined benefit, Defined contribution.

\section{Introduction}

In this paper,I analyzed consumption, aggregate savings, output behavior and also welfare under two popular social security arrangements when ever there is demographic uncertainty. The two popular social security arrangements are Pay as You Go(PAYGO) and Fully Funded(FF) social security. I analyze two variants of each of these social security systems, the Defined Benefit(DB) and the Defined Contribution(DC) arrangements. Under the assumtption of a fixed benefit rate for the DB system and a fixed tax rate for the DC system, I analyze both short run and long run effect of demographic uncertainty. I use a life-cycle model to carry out my analysis. In this setup, the population is divided into two groups, workers and retirees. These two groups are heterogenous in terms of their consumption and savings behavior. All the workers and all the retirees would be ex-ante identical. In the model there is uncertainty about retirement and death. I assume the transitional probability to retirement and death to be constant. In order to introduce short run variation, I introduce a stochastic population growth process for the workers. I consider a permanent increase in the growth rate of the worker population. Longrun analysis reveals contrasting effect of alternative social security system on the consumption, capital accumulation

\footnotetext{
${ }^{*}$ Contact address:Department of Economics,Indiana University at Bloomington,Phone:812-8550179,email:murahman@indiana.edu. I would like to thank my Third year paper committee members, Eric Leeper, Michael Kaganovich, and Brian Peterson for their valuable suggesstions during my research. I would like to specially thank Hess Chung for his critical suggestions, thorough guidence and helpful scrutini of my work. I would also like to acknowledge helpful comments from James Murray and Michael Plante. Finally, I thank all the participants of the Spring 2007 Macroeconomics Brown Bag workshop. All errors are mine
} 
and output. Social security arrangement appears to be in general beneficial for the retiree, but harmful to the worker's consumption. Pension system also dampens output growth and discourages savings. PAYGO-DB appears to fare better than rest of the arrangements, although far worse than the private annuity market without social security or government intervention. This contrasts with the existing literature. In case of the population shock, it appears that Intergenerational risk sharing mechanism like the PAYGO systems provide better risk sharing. But when social welfare is considered, there appears to be clear trade-off between growth and welfare. FF system appears to be welfare maximizing, even when compared with the non distortionary private annuity market. In fact the latter performs the worst in terms of welfare. I also look at speed of convergence of the economy and relate that to the volatility of the system. It appears that social security arrangements in general reduces the volatility of the economy.

\section{Motivation and Literature Review}

In this paper, my plan is to look at the effect of a permanent shock in the growth rate of the work force on the economy under alternative social security systems using a new kind of lifecycle model. Figure 1-5 highlights some of the demographic features and trends in employment in USA. There are several interesting things in the that. First, although population growth has slowed down after the 70's, with unemployment rate at its lowest and with a rapid increasing rate of immigration fueled by positive signal from the policy makers, USA has been experiencing a large influx of fresh and returning entrant into the labor force. An increased immigration to the USA and similar increase in the number of naturalization of aliens definitely have contributed to the improved performance of employment scenario over the changes in the labor force. This is projected to remain at a higher level. Hence analyzing the effect of an increases in the growth rate of workforce force may be a useful exercise. The second motivation comes from the changes in the nature of retirement in USA. Using HRS data, Quinn(1999) estimates that between one-third and one -half of older Americans take on Bridge Jobs(temporary, sometimes lower paid jobs) before exiting labor force completely. He concludes that retirement pattern in America are much richer and more varied than the stereotypical one-step view of retirement suggests. Maestas(2004) finds that more than one-third of retirees in their 50's go back to work after retirement. Using a larger panel data set from the HRS survey, Cahill, Giandrea and Quinn(2005) finds that (Table 1 in appendix) in 1992, 15\% of all the employed worker since age 49 had part time employment. In 2002, in the same population(now ten years older), $25 \%$ of all employed men had part time jobs. In 2000, this fraction was even larger, $33 \%$. We also see similar picture for female. Table-2 reveals some more dramatic results. Out of the men who had full time job in 1992, $40 \%$ of them in 2002 who then over 60 years of age had part time job. Out of the people who were 65 years and older(full retirement age in traditional sense) $37.5 \%$ had part time job. Two important conclusions arise from their findings. First, retirees should no longer be modeled as withdrawing completely from the labor force. Second, it is safe to assume that the part time jobs that traditional retirees get after their retirement pays them a lower effective wage.

In the literature, life-cycle models are popular for analyzing demographic transition. Ever since the development of the life-cycle models by Brumberg, Ando, Modigliani(1956), these models have been extensively used by both policy makers and researchers. With the popularization of Discrete Stochastic General Equilibrium(DSGE) models, there has been attempts to develop a DSGE version of life-cycle model. To my knowledge, the first of such model was developed by Gali(1990) which tried to find evidence of life cycle behavior in a DSGE model by adopting the Blanchard-Yarri model. But in order to avoid problems with aggregation, he assumed an identical(and constant) MPC for the workers and the retirees. Clarida(1991) was able to develop a DSGE life cycle model where he was able to achieve aggregation without assuming constant or identical MPC for all cohorts. My model is very close to Gertler(1999). He developed a DSGE 
life-cycle model which was a modified version of Blachard-Yarri(1965) model where he added a transitional probability to retirement in addition to the original generational index parameter, the transitional probability to death. Gertler's model has different MPC's for different groups. Based on his assumption on the preference structure, Gertler argued that all the works have identical MPC and all the retirees have same MPC. He was then able to aggregate all the consumption functions of workers of different age and did the same thing for all the retirees. This allowed him to derive an aggregate consumption function for the workers and also for the retirees. He also developed aggregate human and non-human wealth functions for the economy and carried out various fiscal experiments. Recently Ferrero(2005), Kilponen, Kinnunen and Ripatti(2006), Keuschigg and Keuschigg(2004), Roeger(2005), Kara and Thadden(2006), Fujivara and Teranish(2006), Grafenhofer, Jaag and Keuschigg(2006) have extended the Gertler(1999) model further and studied different aspects of population ageing in their models. The main advantages of using Gertler's framework is that one can apply various tools used in the Real Business Cycle literature and analyze not only the stationary equilibrium, but also the transition path. But perhaps the most popular Life cycle simulated models were developed by Auerbach and Kotiliokoff(1987) . While analysis of debt in a representative agent might be misleading ${ }^{1}$, the analysis based on the simulated life cycle models does not offer any analytical tractability. Second, other than few authors such as Kotilikoff, most of the researchers focus on various ways to make the existing PAYGO system more efficient. A comparative analysis of major alternative social security system is nearly absent. Kotlikoff, Smetters and Walliser(1999) analyzes the efficacy of alternative privatized social security systems using their famous simulated A-K model. De Nardi,Imrohoroğlu and Sargent(1999) on the other hand analyzes the impact of various fiscal policy measures to the retirement of the baby boomers under the present social security system. Finally, the work closest to my paper are $\operatorname{Bohn}(2002,1999,1998)$ which carry out a comparative analysis of various alternative social security and debt management schemes using an OLG framework. Although his analysis provides significant insight into the efficacy of alternative policy regime, the OLG framework limits its applicability for policy analysis. In a two period stochastic OLG framework, although Bohn uses several RBC tools that I will also employ, I will be able to analyze the entire transition path of the economy before and after a demographic shock which the former was not able to do. The short run efficacy of alternative policy regime is equally important for policy makers. This paper will therefore be a value addition to that literature. My model is also different from the original work by Gertler(1999). His model has social security in the form of a lump-sump tax-transfer scheme. This is clearly unrealistic, as Gertler himself acknowledges. My model will have full specification of various social security regimes. My paper also differs from Gertler(1999) in terms of policy analysis. Gertler focuses mainly on various fiscal experiments like changing the government debt. He also conducts some demographic experiments like changing the dependency ratio by experimenting on transitional probability of death and experimenting on the transition to retirement. My experiments will be different because I will focus only on introducing demographic shock to the growth rate of the workforce. Although my experiments will have similar effect on the dependency ratio as Gertler, the source of that is different. Finally, I will completely obstruct away from introducing any government debt in my model, which is the driving force in Gertler's experiments.

Keeping in mind the above mentioned issues, I plan to develop a DSGE Life cycle model with a fully developed social security system. I would like to incorporate some fundamental uncertainties that were outlined in Bohn(2002) and Gertler(1999). In my model, I would like to analyze how basic uncertainties are shared by the workers and the retirees under alternative social security arrangement. My basic model would be an extended version of Gertler(1999). To introduce life-cycle factors but maintain tractability, Gertler made two kinds of modifications of

\footnotetext{
${ }^{1}$ Romer(1989) suggested that government debt might have very little effect on the real activity in the Blanchard/Weil framework. Gertler(1999) argues that adding life cycle features would enhance the impact
} 
the Blanchard/Weil framework. First, Gertler introduced two stages of life: work and retirement. Gertler then imposed a constant transition probability per period for a worker into retirement, as well as a constant probability per period of death for a retiree. In my model, both the transition probability per period of death and retirement would be stochastic with both following an iid process . Second, Gertler employed a class of non-expected utility preferences proposed by Kreps and Porteus(1978) and later popularized by Farmer (1990), Weil(1990) and Epstein and Zin(1990) that generate certainty-equivalent decision rules in the presence of income risk. Gertler showed that with these two modifications it is possible to derive aggregate consumption/savings relations for workers and for retirees. It is also possible to express the current equilibrium values of all the endogenous variables as functions of just two predetermined variables: the capital stock and the distribution of nonhuman wealth between retirees and workers. In my model, I will focus on the aggregate behavior of the Workers and the Retirees separately and keep track of the evolution of their human(wage income) and non-human(income from savings on capital asset) wealth. Because the model permits realistic average periods of work and retirement, the model is useful for quantitative policy analysis in a way that complements the use of large-scale models. The advantage of this framework is its parsimonious representation, which helps make clear the factors that underlie the results. In particular, it is possible to obtain an analytical solution for aggregate consumption behavior, conditional on the paths of wages and interest rates. In this case with variable work effort, it is also possible to find an analytical solution for aggregate labor supply. Since the effects of government and social security on the economy in this framework work their way through consumption and labor supply, these (partial) analytical solutions will help clarify the nature and strength of the policy transmission mechanisms. Further, because of its parsimony, it is straightforward to integrate this life-cycle setup into existing growth and business-cycle models in order to study a much broader set of issues which have already been starting to be analyzed by many researchers.

\section{Basic feature of the Life-cycle model}

In this model, individuals have finite lives and they evolve through two distinct stages of life: work and retirement. To derive a tractable aggregate consumption function and at the same time permit realistic (average) lengths of work and retirement, I make three kinds of assumptions. These assumptions involve: (1) population dynamics; (2) insurance arrangements; and (3) preferences.

\subsection{Demographic feature}

The population dynamics will follow a natural ordering to allow for tractability of our model. Consumers are assumed to be born as workers. Workers face a constant retirement probability $\omega$.Conditional on being a worker in the current period, the probability of remaining one in the next period is $\omega$; while the probability of retiring is $1-\omega$. These transition probabilities are independent on individual's employment tenure. Once an individual has retired he is facing a periodic probability of death $1-\gamma$. The survival probability is assumed to be independent of retirement tenure. Let us denote $N_{t}^{w}$ and $N_{t}^{r}$ to be the total number of workers and retirees. In period $t+1$,I assume that there would be $\left(1+n_{t+1}-\omega\right)$ new workers born, where $n_{t}$ is another white noise process with mean $n$ and a variance $\sigma^{2}$. Hence the workers' population follows the following law of motion:

$$
N_{t+1}^{w}=\left(1+n_{t+1}-\omega\right) N_{t}^{w}+\omega N_{t}^{w}=\left(1+n_{t+1}\right) N_{t}^{w}
$$

The retiree population follows law of motion: 


$$
N_{t+1}^{r}=(1-\gamma) N_{t}^{r}+(1-\omega) N_{t}^{w}
$$

Define $\psi_{t}=\frac{N_{t}^{r}}{N_{t}^{w}}$ to be the ratio of retiree to the worker, the dependency ratio. Using equation(1) and (2), we can show that the dependency ratio follows law of motion:

$$
\psi_{t+1}\left(1+n_{t+1}\right)=\gamma \psi_{t}+(1-\omega)
$$

By using equation(3) we can drive the following:

$$
\begin{gathered}
\frac{N_{t+1}^{w}}{N_{t}^{w}}=\left(1+n_{t+1}\right) \\
\frac{N_{t+1}^{r}}{N_{t}^{r}}=\left(1+n_{t+1}\right) \frac{\psi_{t+1}}{\psi_{t}} \\
\frac{N_{t+1}}{N_{t}}=\left(1+n_{t+1}\right) \frac{1+\psi_{t+1}}{1+\psi_{t}} \\
\ln n_{t+1}=\rho_{n} \ln n_{t}+e_{1 t+1}, 0<\rho_{n}<1
\end{gathered}
$$

Where $N_{t}$ is the total population at time $t$ which is simply defined as follows

$$
N_{t}=N_{t}^{r}+N_{t}^{w}
$$

Furthermore, in the stationary equilibrium, $\psi_{t+1}=\psi_{t}=\psi, n_{t+1}=n$. Then $N_{t+1}^{w}, N_{t+1}^{r}$ and $N_{t+1}$ all grow at the same rate $n$ and the population dynamics in this model is stationary.

\subsection{Insurance Market}

To eliminate the impact of uncertainty about time of death, I introduce a perfect annuities market, following Yaari (1965) and Blanchard (1985). The annuities market provides perfect insurance against this kind of uncertainty. Under the arrangement, each retiree effectively turns over his wealth to a mutual fund that invests the proceeds. The fraction $\gamma$ of those that survive to the next period receive all the returns, while the (estates of) the fraction $1-\gamma$ who die receive nothing. Each surviving retiree receives a return that is proportionate to his initial contribution of wealth to the mutual fund. Thus, for example, if $R_{t+1}$ is the gross return per dollar invested by the mutual fund, the gross return on wealth for a surviving retiree is $\frac{R_{t}+1}{\gamma}$.

\subsection{Preference}

Now the timing of economic decisions are very important. Each persons make all his decisions at the beginning of time, all his decisions are ex-ante. Now we will define the utility function of an individual who derives utility from consumption, $c$ and leisure $(1-l)$. Following Kreps and Porteus(1978), and Farmer(1990), we will use a special class CES non-expected utility function. The parametric form of the utility function will be following Weil(1990)

$$
V_{t}^{z}\left(a_{t-1}\right)=\left\{U\left(c_{t}^{z}, l_{t}^{z}\right)^{\rho}+\beta_{t+1}^{z} E_{t}\left[V_{t+1}\left(a_{t}\right) \mid z\right]^{\frac{\rho}{\alpha}}\right\}^{\frac{1}{\rho}}
$$

This preference structure has the convenient property of separating between the elasticity of inter temporal substitution given by $\sigma=\frac{1}{(1-\rho)}$ and the coefficient of relative risk aversion, given 
by $\alpha$. Following Gertler(1999) and Ferrero(2005), we assume $\alpha=1$. Then equation (8) can be written as:

$$
V_{t}^{z}\left(a_{t-1}\right)=\left\{U\left(c_{t}^{z}, l_{t}^{z}\right)^{\rho}+\beta_{t+1}^{z} E_{t}\left[V_{t+1}\left(a_{t}\right) \mid z\right]^{\rho}\right\}^{\frac{1}{\rho}}
$$

According to Farmer(1990), These preferences generate certainty-equivalent decisions rules in the face of idiosyncratic income risk, in contrast to standard Von-Neumann/Morgenstern utility functions. Roughly speaking, because preferences are over the mean of next period's value function, individuals only care about the first moment of expected income in deriving their decision rules) ${ }^{2}$. On the other hand, they do care about smoothing consumption over time. The curvature parameter $\rho$ introduces a smooth trade-off for individuals between consuming today versus consuming tomorrow. In analogy to the standard case, the desire to smooth consumption implies a finite inter temporal elasticity of substitution, given by $\sigma=\frac{1}{(1-\rho)}$. Thus a virtue of the preference structure is that it permits flexibility over the choice of $\sigma$, which is a key parameter in determining the quantitative effects of debt and social security. Furthermore, Weil(1990) argues that the value of $\rho$ determines people's attitude towards intertemporal substitution, or inter temporal consumption smoothing. $\rho<1$ means Income effects are smaller than Substitution effect and vice versa for $\rho>1$. This certainty-equivalent analysis clarifies the respective role of risk aversion and inter temporal substitution. The substitution effect depresses the marginal propensity to save as soon as agents are risk averse, as the optimum way to maintain the original utility level when wage income risk increases is to consume more today (and thus avoid facing the increased risk). The income effect is simply a precautionary savings effect, whose magnitude depends on the inter temporal elasticity of substitution: increased wage risk implies a higher probability of low consumption tomorrow, against which consumers will protect themselves the more, by consuming less, the more averse they are to inter temporal fluctuations of consumption. Which of these two conflicting effects dominates depends on the strength of the precautionary motive, i.e., on the magnitude of the inter temporal elasticity of substitution.

Finally, we assume the period utility function is Cobb-Douglas. With that the recursive utility function of the agents in the model:

$$
V_{t}^{z}\left(a_{t-1}\right)=\left\{\left[\left(C_{t}^{z}\right)^{v}\left(1-l_{t}^{z}\right)^{1-v}\right]^{\rho}+\beta_{t+1}^{z} E_{t}\left[V_{t+1}\left(a_{t}\right) \mid z=w, r\right]^{\rho}\right\}^{\frac{1}{\rho}}
$$

Where:

$$
\begin{gathered}
E_{t}\left[V_{t+1}\left(a_{t} \mid w\right)\right]=\omega V_{t+1}^{w}+(1-\omega) V_{t+1}^{r}, \beta_{t+1}^{w}=\beta \\
E_{t}\left[V_{t+1}\left(a_{t} \mid r\right)\right]=V_{t+1}^{r}, \beta_{t+1}^{r}=\beta \gamma
\end{gathered}
$$

Therefore, this preference representation now has conveniently separated period elasticity of substitution $v$ and inter temporal elasticity of substitution $\sigma$ for consumption.

Now I will proceed to solve the optimization problem by both the worker and the retiree. Both worker and retiree have 1 unit of time which they allocate between work $(l)$ and leisure. Both receive the same wage $W_{t}$. But the retirees are less productive than the worker, which will be reflected by a productivity parameter $\theta$.

\footnotetext{
${ }^{2}$ Since retirees do not face any income risk, they behave as if they had standard Von- Neumann/Morgenstern preferences. In other words, the solution to their decision problem is the same as if they had standard preferences.
} 


\section{Model with Private Annuity Market}

In the baseline mode, we will consider optimization by the agents without any government intervention. There will only be an annuity market .

\subsection{Optimization by the Retiree}

Retirees consume out of asset income and labour income. In general, one can index each retiree by the time he was born $j$ and the time he left the labor force $k$. Ultimately, it will not be necessary to keep track of how assets and consumption are distributed among retirees over $j$ and

$k$. Under my assumptions one can simply aggregate across different cohorts. Let $A_{t}^{r j k}$ and $C_{t}^{r j k}$ be the assets at the beginning of time $t$ and consumption at $t$, respectively, of a retired person who was born at time $j$ and left the labor force at time $k$; and let $R_{t}$ be the gross return on assets from period $t-1$ to $t$. For a retiree at $t$ who participates in a perfect annuities market, his optimization problem looks like:

$$
\underset{\left\{C^{r j k}, l^{r j k}\right\}}{V_{t}^{r j k}\left(A_{t-1}^{r}\right)}=\left\{\left[\left(C_{t}^{r j k}\right)^{v}\left(1-l_{t}^{r j k}\right)^{1-v}\right]^{\rho}+\beta \gamma\left[V_{t+1}^{r}\left(A_{t}^{r}\right)\right]^{\rho}\right\}^{\frac{1}{\rho}}
$$

Subject to:

$$
A_{t}^{r j k}=\frac{R_{t} A_{t-1}^{r j k}}{\gamma}+W_{t} \theta l_{t}^{r j k}-C_{t}^{r j k}
$$

With $0 \prec \theta \prec 1$.

Following Gertler(2000), the consumer's optimization has to satisfy additional conditions. The first one is as follows:

$$
\lim _{i \rightarrow \infty} E_{t} \frac{\gamma^{i} R_{t+i} A_{t+i-1}^{r j k}}{\prod_{j=1}^{i} R_{t+j}}=0
$$

The above equation is meant to rule out Ponzi schemes. The individual has to satisfy an intertemporal budget constraint. He eventually has to pay off any debt, he cannot continuously play with Ponzi schemes. As it turns out, the above condition is not sufficient. We need a stronger condition for optimization under uncertainty. The infinite horizon budget constraint now has to hold in expectations. It has to hold both in ex-ante and ex-post sense since the individual is allowed to borrow only at riskless rate. It has to hold for every possible realization of $W_{t}$ and $R_{t}$ which are essentially random variables. Thus the individual can borrow risklessly but has to be able to pay back the debt. Therefore, the optimization problem of retiree has to satisfy the following intertemporal budget constraint:

$$
E_{t}\left[\sum_{i=0}^{\infty} \frac{\gamma^{i} C_{t+i}^{r j k}}{\prod_{j=1}^{i} R_{t+j}}\right]=\frac{R_{t} A_{t-1}^{r j k}}{\gamma}+H_{t}^{r j k}
$$

Where $H_{t}^{r j k}$ is the expected lifetime labor income of the retiree defined later.

We also need the following requirement:

$$
\lim \underset{i \rightarrow \infty}{E_{t}}\left\{R_{t+i}\right\}=\bar{R}, \lim \underset{i \rightarrow \infty}{E_{t}}\left\{W_{t+i}\right\}=\bar{W}
$$


Where the last condition is a stationary condition on the $\left\{W_{t}\right\}_{t=0}^{\infty}$ process.

The first order condition with respect $C_{t}^{r}$ along with respective envelope conditions ${ }^{3}$ yields the following euler equation for the retiree:

$$
C_{t+1}^{r j k}=\left[\left(\frac{W_{t+1}}{W_{t}}\right)^{\rho(1-v)}\left(\beta R_{t+1}\right)\right]^{\sigma} C_{t}^{r j k}
$$

The first order condition with respect to $l_{t}^{r j k}$ along with respective envelope conditions yields the following conditions:

$$
l_{t}^{r j k}=1-\frac{\mu}{\theta W_{t}} C_{t}^{r j k}
$$

where

$$
\mu=\frac{1-v}{v}
$$

In order to derive a decision rule for the retiree we employ Modigliani(1963) idea that a person consumes a fraction of this life time income. Therefore, I guess that the consumption function looks like:

$$
C_{t}^{r j k}=\xi_{t}\left(\frac{R_{t} A_{t-1}^{r j k}}{\gamma}+H_{t}^{r j k}\right)
$$

Where $\xi_{t}$ is the marginal propensity to consume(MPC) out of life income for the retiree. $A_{t-1}^{r}$ is the total non-human asset accumulated up to time $t$ and $H_{t}^{r}$ is the expected lifetime labour income for the retiree, which is given by:

$$
H_{t}^{r j k}=\sum_{n=0}^{\infty} \frac{\gamma^{n} W_{t+n} \theta l_{t+n}^{r j k}}{\prod_{z=0}^{n} R_{t+z+1}}=\theta W_{t} l_{t}^{r}+\frac{\gamma H_{t+1}^{r j k}}{R_{t+1}}
$$

We will also guess the following form for the $v_{t}^{r}$,

$$
V_{t}^{r j k}=\Delta_{t}^{r} C_{t}^{r j k}\left(\frac{\mu}{\theta W_{t}}\right)^{1-v}
$$

After some math, we can prove the following:

$$
\Delta_{t}^{r}=\left(\xi_{t}\right)^{\frac{-1}{\rho}}
$$

Also, the MPC follows the following law of motion:

$$
\xi_{t}=1-\left(\frac{W_{t}}{W_{t+1}}\right)^{\rho \sigma(1-v)} \beta^{\sigma} R_{t+1}^{\sigma-1} \gamma \frac{\xi_{t}}{\xi_{t+1}}
$$

\subsection{Optimization by the Worker}

The worker's maximization problem looks like:

$$
\underset{\left\{C^{w j k}, l^{w j k}\right\}}{V_{t}^{w j k}\left(A_{t-1}^{w}\right)}=\left\{\left[\left(C_{t}^{w j k}\right)^{v}\left(1-l_{t}^{w j k}\right)^{1-v}\right]^{\rho}+\beta\left[\omega V_{t+1}^{w}\left(A_{t}^{w j k}\right)+(1-\omega) V_{t+1}^{r}\left(A_{t}^{w^{r} j k}\right)\right]^{\rho}\right\}^{\frac{1}{\rho}}
$$

\footnotetext{
${ }^{3}$ For a detailed derivation, please see the appendix 1
} 
Subject to:

$$
\begin{gathered}
A_{t}^{w j k}=R_{t} A_{t-1}^{w j k}+W_{t} l_{t}^{w j k}-C_{t}^{w j k} \\
A_{t}^{w^{r} j k}=R_{t} A_{t-1}^{w j k}-C_{t}^{w j k}
\end{gathered}
$$

where the second budget constraint is for the worker who was worker today $(t)$ but will become retiree tomorrow $(t+1)$. As a result, this new retiree was not able to put his wealth into the annuity market. Also, when the workers of period t retires at period $t+1$, he will no longer have his labour income as a worker.

Similar to the retiree, we need Ponzi constraint for the worker which looks like:

$$
\lim _{i \rightarrow \infty} E_{t} \frac{R_{t+i} A_{t+i-1}^{w j k}}{\prod_{j=1}^{i} \Omega_{t+i} R_{t+j}}=0
$$

Where $\Omega_{t+i}$ is an additional factor that is used to weight the gross interest rate, to be defined later. This will along with equation(16) give us an intertemporal budget constraint for the worker which looks like:

$$
E_{t}\left[\sum_{i=0}^{\infty} \frac{C_{t+i}^{w j k}}{\prod_{j=1}^{i} \Omega_{t+i} R_{t+j}}\right]=R_{t} A_{t-1}^{w j k}+H_{t}^{w j k}
$$

The problem of the worker is quite complicated and the first order conditions are messy. In order to simplify our calculation, We will guess that the consumption function looks like:

$$
C_{t}^{w j k}=\pi_{t}\left(R_{t} A_{t-1}^{w j k}+H_{t}^{w j k}\right)
$$

Where $\pi_{t}$ is the marginal propensity to consume out of life income for the worker. $A_{t-1}^{w j k}$ is the total non-human asset accumulated up to time $t$ and $H_{t}^{w j k}$ is the expected lifetime labour income for the retiree, which is given by:

$$
H_{t}^{w j k}=W_{t} l_{t}^{w j k}+\frac{\omega H_{t+1}^{w j k}}{\Omega_{t+1} R_{t+1}}+\frac{(1-\omega) H_{t+1}^{r j k}}{\Omega_{t+1} R_{t+1}}
$$

where:

$$
\Omega_{t+1}=\omega+(1-\omega) \epsilon_{t+1}^{\frac{1}{1-\sigma}}
$$

where:

$$
\epsilon_{t+1}=\frac{\xi_{t+1}}{\pi_{t+1}}
$$

and $\pi_{t}$ follows the following law of motion:

$$
\pi_{t}=1-\left(\frac{W_{t}}{W_{t+1}}\right)^{(1-v) \rho \sigma}\left(R_{t+1} \Omega_{t+1}\right)^{\sigma-1} \frac{\pi_{t}}{\pi_{t+1}}
$$

Now we will guess a functional form for $V_{t}^{w j k}$ : 


$$
V_{t}^{w j k}=\Delta_{t}^{w} C_{t}^{w j k}\left(\frac{\mu}{W_{t}}\right)^{1-v}
$$

The first order condition with respect to $C_{t}^{w j k}$ along with respective envelope conditions and equation(30)yields the following euler equation:

$$
\begin{gathered}
\omega C_{t+1}^{w j k}+(1-\omega) \chi\left(\epsilon_{t+1}\right)^{\frac{\sigma}{1-\sigma}} C_{t+1}^{r j k}= \\
{\left[\left(\frac{W_{t}}{W_{t+1}}\right)^{\rho \sigma(1-v)} \beta^{\sigma} R_{t+1}\left\{\omega+(1-\omega) \chi\left(\epsilon_{t+1}\right)^{\frac{\sigma}{1-\sigma}}\right\}^{\frac{1}{1-\sigma}}\right]^{\sigma} C_{t}^{w j k}}
\end{gathered}
$$

where:

$$
\chi=\left(\frac{1}{\theta}\right)^{1-v}
$$

Finally, the first order condition for $l_{t}^{w j k}$ looks like

$$
l_{t}^{w j k}=1-\frac{\mu}{W_{t}} C_{t}^{w j k}
$$

\subsection{Derivation of Aggregate Functions}

If we look at the consumption functions for a workers, we see two things. First, the MPC at time period $t$ will be the same for all the workers. Second, The only thing that will differ is their lifetime accumulated income which will vary with each cohort. We can therefore, proceed to aggregate the consumption for all the workers for a given period $t$. We will first drop all the $j$ and $k$ subscript and derive some more aggregate variables:

Total labor supply by workers

$$
\begin{aligned}
L_{t}^{w} & =\sum_{i=0}^{N^{w}} l_{t}^{w}(i)=\sum_{i=0}^{N^{w}}\left[1-\frac{\mu}{W_{t}} C_{t}^{w}(i)\right] \\
& =N_{t}^{w}-\sum_{i=0}^{N^{w}} \frac{\mu}{W_{t}} C_{t}^{w}(i)=N_{t}^{w}-\frac{\mu}{W_{t}} C_{t}^{w}
\end{aligned}
$$

Total labour supply by the retirees:

$$
L_{t}^{r}=\sum_{i=0}^{N^{r}} l_{t}^{r}(i)=N_{t}^{r}-\sum_{i=0}^{N^{r}} \frac{\mu}{\theta W_{t}} C_{t}^{r}(i)=N_{t}^{r}-\frac{\mu}{\theta W_{t}} C_{t}^{r}
$$

The aggregate effective labour supply to the economy:

$$
L_{t}=L_{t}^{w}+\theta L_{t}^{r}
$$

Aggregate non-human wealth by all worker at time t:

$$
A_{t-1}^{w}=\sum_{i=0}^{N^{w}} A_{t-1}^{w}(i)
$$

The aggregate life time labor income of the workers at time $t$

$$
H_{t}^{w}=W_{t} L_{t}^{w}+\frac{\omega H_{t+1}^{w}}{\left(1+n_{t+1}\right) \Omega_{t+1} R_{t+1}}+\frac{(1-\omega) H_{t+1}^{r}}{\left(1+n_{t+1}\right) \Omega_{t+1} R_{t+1} \psi_{t+1}}
$$


By summing up the individual guess function for Consumption, we can derive the aggregate consumption function for workers

$$
C_{t}^{w}=\pi_{t}\left(R_{t} A_{t-1}^{w}+H_{t}^{w}\right)
$$

Similarly, we can derive aggregate relationships for the retirees:

$$
\begin{gathered}
C_{t}^{r}=\xi_{t}\left(R_{t} A_{t-1}^{r}+H_{t}^{r}\right) \\
H_{t}^{r}=\theta W_{t} L_{t}^{r}+\frac{\gamma H_{t+1}^{r} \psi_{t}}{R_{t+1} \psi_{t+1}}
\end{gathered}
$$

The aggregate wealth of the economy for the workers and the retirees look like:

$$
\begin{gathered}
A_{t}^{r}=A_{t-1}^{r} R_{t}+\theta W_{t} L_{t}^{r}-C_{t}^{r}-(1-\omega)\left(A_{t-1}^{w} R_{t}+W_{t} L_{t}^{w}-C_{t}^{w}\right) \\
A_{t}^{w}=\omega\left(A_{t-1}^{w} R_{t}+W_{t} L_{t}^{w}-C_{t}^{w}\right) \\
C_{t}=C_{t}^{w}+C_{t}^{r}
\end{gathered}
$$

Let us define $A_{t-1}$ as the aggregate wealth of the economy at period $t$ and $\lambda_{t-1}=\frac{A_{t-1}^{r}}{A_{t-1}}$ as the share of the asset held by the retirees. It also follows that $1-\lambda_{t-1}=\frac{A_{t-1}^{w}}{A_{t-1}}$. Using these two and also equation (41) and (42)we can rewrite the aggregate wealth of the economy as follows

$$
A_{t}\left(\frac{\lambda_{t}}{\omega}-\frac{1-\omega}{\omega}\right)=R_{t} \lambda_{t-1} A_{t-1}+\theta W_{t} L_{t}^{r}-C_{t}^{r}
$$

Finally, using the definition of the aggregate wealth, equation (38) and (39) looks like:

$$
\begin{gathered}
C_{t}^{w}=\pi_{t}\left[R_{t}\left(1-\lambda_{t-1}\right) A_{t-1}+H_{t}^{w}\right] \\
C_{t}^{r}=\xi_{t}\left[R_{t} \lambda_{t-1} A_{t-1}+H_{t}^{r}\right]
\end{gathered}
$$

\subsection{Production side of the economy}

Production is subject to a neoclassical production function with labour augmenting technological progress:

$$
Y_{t}=\left(X_{t} L_{t}\right)^{\alpha} K_{t-1}^{1-\alpha}
$$

where the technology follows an $\mathrm{AR}(1)$ process:

$$
\ln X_{t+1}=\rho_{x} \ln X_{t}+e_{1 t+1}, 0<\rho_{x}<1
$$

The wage rate and return on capital are determined as:

$$
\begin{gathered}
W_{t}=\alpha \frac{Y_{t}}{L_{t}} \\
R_{t}=(1-\alpha) \frac{Y_{t}}{K_{t-1}}+(1-\delta)
\end{gathered}
$$


Capital evolves according to the following law of motion:

$$
K_{t}=Y_{t}-C_{t}+(1-\delta) K_{t-1}
$$

Finally we close the model by specifying the relationship between the capital stock and the wealth $^{4}$ :

$$
K_{t}=A_{t} \forall t
$$

\subsection{Definition of Competitive Equilibrium}

A competitive equilibrium is a sequence of endogenous predetermined variables $\left\{K_{t-1}, A_{t-1}^{r}, A_{t-1}^{w}\right\}$ and a sequence

of endogenous variables $\left\{\pi_{t}, \xi_{t}, \Omega_{t}, H_{t}^{r}, H_{t}^{w}, C_{t}^{w}, C_{t}^{r}, W_{t}, R_{t}, A_{t}^{w}, A_{t}^{r}\right\}$, that satisfy equations 3756 , given the sequence of the exogenous predetermined variables $\left\{N_{t+1}, X_{t+1}\right\}$ specified by (6) and (59), and given the initial values of all the predetermined variables, $\mathrm{K}_{t}, \mathrm{~A}_{t}, \mathrm{~N}_{t}$, and $\mathrm{X}_{t}$.

\section{Model with PAYGO-Defined Benefit Social Security System}

In the PAYGO model we will consider optimization where there is a PAYGO social security system for the retiree. The role of the government will be to carry out this transfer to the present retirees by taxing the present workers. The government will impose a payroll tax on the workers. The retirees, although working, are not subject to the payroll tax. The benefit which will include a participation rate which will determine how much transfer the retirees receive will be fixed in the defined benefit case. The above two are assumptions of the model where the former is made to simplify the solution of the model and the latter is a specification used in the literature. The income of the retirees will still be annuitized so that accidental bequest is prevented.

\subsection{Optimization by the Retiree}

The optimization problem by the retiree looks very similar to the baseline case except for the fact that the retirees now also receive a social security payment $E_{t}^{r j k}=B W_{t}$, where $B$ is a fixed defined benefit rate, or the participation rate. For a retiree at $t$ who participates in a perfect annuities market, his optimization problem looks like:

$$
\begin{aligned}
& V_{t}^{r j k}\left(A_{t-1}^{r}\right)=\left\{\left[\left(C_{t}^{r j k}\right)^{v}\left(1-l_{t}^{r j k}\right)^{1-v}\right]^{\rho}+\beta \gamma\left[V_{t+1}^{r}\left(A_{t}^{r}\right)\right]^{\rho}\right\}^{\frac{1}{\rho}} \\
& \left\{C^{r j k}, l^{r j k}\right\}
\end{aligned}
$$

Subject to:

\footnotetext{
${ }^{4}$ In order to see that equation(56) holds, lets add up equation (45) and (46), and we get $A_{t}^{r}+A_{t}^{w}=R_{t}\left(A_{t-1}^{r}+A_{t-1}^{w}\right)+W_{t}\left(\theta L_{t}^{r}+L_{t}^{w}\right)-C_{t}^{r}-C_{t}^{w}$

Using the fact that, $A_{t-1}=A_{t-1}^{r}+A_{t-1}^{w}$ for $t$ and $t-1$ and equation (39), and substituting the value of $R_{t}$ and $W_{t}$ from equation (53) and (54), the above equation can be written as:

$A_{t}=(1-\alpha) \frac{Y_{t}}{K_{t-1}} A_{t-1}+(1-\delta) K_{t-1}+\alpha \frac{Y_{t}}{L_{t}} L_{t}--C_{t}^{r}-C_{t}^{w}$

Now if $K_{t-1}=A_{t-1}$, then the above equation can be written as:

$A_{t}=Y_{t}+(1-\delta) K_{t-1}-C_{t}^{r}-C_{t}^{w}$

Where the right hand side of the eqaution is identical to the right hand side of equation (55). Therefore, $K_{t}=A_{t}$
} 


$$
A_{t}^{r j k}=\frac{R_{t} A_{t-1}^{r j k}}{\gamma}+W_{t} \theta l_{t}^{r j k}-C_{t}^{r j k}+B W_{t}
$$

With $0 \prec \theta \prec 1$.

Similar to the private annuity market case, the retirees will have a Ponzi constraint like equation(14). Their intertemporal budget constraint now looks like:

$$
E_{t}\left[\sum_{i=0}^{\infty} \frac{\gamma^{i} C_{t+i}^{r j k}}{\prod_{j=1}^{i} R_{t+j}}\right]=\frac{R_{t} A_{t-1}^{r j k}}{\gamma}+H_{t}^{r j k}+S_{t}^{r j k}
$$

Where $S_{t}^{r j k}$ is expected lifetime social security payment to the retiree, to be defined later. The first order condition with respect $C_{t}^{r}$ along with respective envelope conditions yields very similar Euler equation for the retiree:

$$
C_{t+1}^{r j k}=\left[\left(\frac{W_{t}}{W_{t+1}}\right)^{\rho(1-v)}\left(\beta R_{t+1}\right)\right]^{\sigma} C_{t}^{r j k}
$$

The first order condition with respect to $l_{t}^{r j k}$ along with respective envelope conditions yields the following conditions:

$$
l_{t}^{r j k}=1-\frac{\mu}{\theta W_{t}} C_{t}^{r j k}
$$

where $\mu$ is defined in equation(18)

Similar to the baseline case, I guess that the consumption function looks like:

$$
C_{t}^{r j k}=\xi_{t}\left(\frac{R_{t} A_{t-1}^{r j k}}{\gamma}+H_{t}^{r j k}+S_{t}^{r j k}\right)
$$

Where $\xi_{t}$ is the marginal propensity to consume(MPC) out of life income for the retiree. $A_{t-1}^{r}$ is the total non-human asset accumulated up to time $t$ and $H_{t}^{r}$ is the expected lifetime labour income for the retiree, defined in equation $(21)$ and $S_{t}^{r j k}$ is the expected lifetime social security payment which is given by:

$$
S_{t}^{r j k}=\sum_{v=0}^{\infty} \frac{\frac{\gamma^{v} E_{t+v}^{r}}{N_{t+v}^{r}}}{\prod_{z=0}^{v} R_{t+z+1}}=\frac{E_{t}^{r}}{N_{t}^{r}}+\frac{\gamma S_{t+1}^{r j k}}{R_{t+1}}
$$

Lets explain the term on the right hand side of the equation (62). $E_{t+v}^{r}=N_{t+v}^{r} B W_{t+v}$ is the total social security payments that all the retirees expect to get paid at some period in the future $t+v$.In order to get the individual transfer, we divide it by the total retiree population in period $t+v$. This individual payment is conditional on the fact that the retiree survives up to period $v$. That is why $\gamma^{v}$ is multiplied with the individual transfer. Finally, we have to discount the transfer to get the present value all future social security payment. This explains the discounting term in the denominator.

We will also have similar guess of the following form for the $v_{t}^{r}$,

$$
V_{t}^{r j k}=\Delta_{t}^{r} C_{t}^{r j k}\left(\frac{\mu}{\theta W_{t}}\right)^{1-v}
$$

Where we can again prove that 


$$
\Delta_{t}^{r}=\left(\xi_{t}\right)^{\frac{-1}{\rho}}
$$

Finally, the MPC follows the same law of motion as with the baseline case

$$
\xi_{t}=1-\left(\frac{W_{t}}{W_{t+1}}\right)^{\rho \sigma(1-v)} \beta^{\sigma} R_{t+1}^{\sigma-1} \gamma \frac{\xi_{t}}{\xi_{t+1}}
$$

\subsection{Optimization by the Worker}

The worker's problem would also be similar except now he has to pay a payroll tax on his wage income. We will assume that the worker pays a constant payroll tax $\tau$ on his wage income. The worker's maximization problem looks like:

$$
\underset{\left\{C^{w j k}, l^{w j k}\right\}}{V_{t}^{w j k}\left(A_{t-1}^{w}\right)}=\left\{\left[\left(C_{t}^{w j k}\right)^{v}\left(1-l_{t}^{w j k}\right)^{1-v}\right]^{\rho}+\beta\left[\omega V_{t+1}^{w}\left(A_{t}^{w j k}\right)+(1-\omega) V_{t+1}^{r}\left(A_{t}^{w^{r} j k}\right)\right]^{\rho}\right\}^{\frac{1}{\rho}}
$$

Subject to:

$$
\begin{gathered}
A_{t}^{w j k}=R_{t} A_{t-1}^{w j k}+\left(1-\tau_{t}\right) W_{t} l_{t}^{w j k}-C_{t}^{w j k} \\
A_{t}^{w^{r} j k}=R_{t} A_{t-1}^{w j k}-C_{t}^{w j k}
\end{gathered}
$$

where the intuition behind the equation(67) and (68) was explained in the previous section. The Ponzi constraint of the worker is same as the private annuity case. Now the intertemporal budget constraint looks like the following:

$$
E_{t}\left[\sum_{i=0}^{\infty} \frac{C_{t+i}^{w j k}}{\prod_{j=1}^{i} \Omega_{t+i} R_{t+j}}\right]=R_{t} A_{t-1}^{w j k}+H_{t}^{w j k}+S_{t}^{w j k}
$$

Where $S_{t}^{w j k}$ is expected lifetime social security payment to the worker, to be defined later. We will again guess that the consumption function looks like:

$$
C_{t}^{w j k}=\pi_{t}\left(R_{t} A_{t-1}^{w j k}+H_{t}^{w j k}+S_{t}^{w j k}\right)
$$

Where $\pi_{t}$ is the marginal propensity to consume out of life income for the worker. $A_{t-1}^{w j k}$ is the total non-human asset accumulated up to time $t$ and $H_{t}^{w j k}$ is the expected lifetime labour income for the retiree, which is given by:

$$
H_{t}^{w j k}=W_{t} l_{t}^{w j k}+\frac{\omega H_{t+1}^{w j k}}{\Omega_{t+1} R_{t+1}}+\frac{(1-\omega) H_{t+1}^{r j k}}{\Omega_{t+1} R_{t+1}}
$$

where $\Omega_{t+1}$ has been defined in the last section. Now $S_{t}^{w j k}$ is the present value of expected lifetime social security that the workers will receive when they retire. $S_{t}^{w j k}$ will be defined as follows:

$$
S_{t}^{w j k}=\sum_{v=0}^{\infty} \frac{\frac{\omega^{v}(1-\omega) S_{t+v+1}^{r}}{\Omega_{t+v+1}^{r} R_{t+v+1}} \frac{\xi_{t+v+1}}{\pi_{t+v+1}}}{\prod_{z=0}^{v} R_{t+z+1} \Omega_{t+z+1}}=\frac{(1-\omega) S_{t+1}^{r}}{N_{t+1}^{r} \Omega_{t+1} R_{t+1}} \frac{\xi_{t+1}}{\pi_{t+1}}+\frac{\omega S_{t+1}^{w j k}}{\Omega_{t+1} R_{t+1}}
$$


Lets explain the term on the right hand side of the equation(71). If the worker retires in period $t+v+1$, he will receive a social security payment of $S_{t+v+1}^{r}$ divided by the population at

$t+v+1$. So, $\frac{S_{t+v+1}^{r}}{N_{t+v+1}^{r} \Omega_{t+v+1} R_{t+v+1}} \frac{\xi_{t+v+1}}{\pi_{t+v+1}}$ is the capitalized value of the social security for a worker who was working at period $t+v$ and retired at $t+v+1$.In order to receive that social security payment, the person has to be a worker up to period $t+v$ and then retires with probability $(1-\omega)$ at $t+v+1$. This explains why $\omega^{v}(1-\omega)$ is multiplied with the capitalized value. Finally, in order to get the present value of the social security payment at period $t$, we have discount this future payment. This explains the discounting factor that appears in the denominator of equation(71).

The law of motion for $\pi_{t}$ looks like:

$$
\pi_{t}=1-\left(\frac{\left(1-\tau_{t}\right) W_{t}}{\left(1-\tau_{t+1}\right) W_{t+1}}\right)^{(1-v) \rho \sigma}\left(R_{t+1} \Omega_{t+1}\right)^{\sigma-1} \frac{\pi_{t}}{\pi_{t+1}}
$$

We will have similar guess about the functional form for $V_{t}^{w j k}$ :

$$
V_{t}^{w j k}=\Delta_{t}^{w} C_{t}^{w j k}\left(\frac{\mu}{\left(1-\tau_{t}\right) W_{t}}\right)^{1-v}
$$

The first order condition with respect to $C_{t}^{w j k}$ along with respective envelope conditions and equation(30)yields the following Euler equation:

$$
\begin{gathered}
\omega C_{t+1}^{w j k}+(1-\omega) \chi\left(\epsilon_{t+1}\right)^{\frac{\sigma}{1-\sigma}} C_{t+1}^{r j k}= \\
{\left[\left(\frac{\left(1-\tau_{t}\right) W_{t}}{\left(1-\tau_{t+1}\right) W_{t+1}}\right)^{\rho \sigma(1-v)} \beta^{\sigma} R_{t+1}\left\{\omega+(1-\omega) \chi\left(\epsilon_{t+1}\right)^{\frac{\sigma}{1-\sigma}}\right\}^{\frac{1}{1-\sigma}}\right]^{\sigma} C_{t}^{w j k}}
\end{gathered}
$$

where $\chi$ is defined in the previous section.

Finally, the first order condition for $l_{t}^{w j k}$ looks like very similar to the baseline case

$$
l_{t}^{w j k}=1-\frac{\mu}{\left(1-\tau_{t}\right) W_{t}} C_{t}^{w j k}
$$

\subsection{Derivation of Aggregate Functions}

In the case of the PAYGO-DB system, there will be an additional aggregate constraints, the government budget. Following Bohn(2002), the government uses fixed pension benefit financed by a payroll tax on the current workers. Taxes and Benefits are conveniently stated in terms of a payroll tax rate $\tau_{t}$ and a fixed replacement rate $B$.Denoting $\tau_{t} W_{t} L_{t}^{w}$ real value of aggregate tax revenue from the worker and $E_{t}^{r}=N_{t}^{r} B W_{t}$ to be the real value of aggregate social security payment to the retiree, the Government Budget constraint looks like

$$
N_{t}^{r} B W_{t}=\tau_{t} W_{t} L_{t}^{w}
$$

In order to derive the rest of the aggregate relationships, we aggregate equations $60-75$ according to their respective populations and get the following

$$
\begin{gathered}
L_{t}^{w}=N_{t}^{w}-\frac{\mu}{\left(1-\tau_{t}\right) W_{t}} C_{t}^{w} \\
L_{t}^{r}=N_{t}^{r}-\frac{\mu}{\theta W_{t}} C_{t}^{r}
\end{gathered}
$$




$$
\begin{gathered}
C_{t}^{w}=\pi_{t}\left[R_{t}\left(1-\lambda_{t-1}\right) A_{t-1}+H_{t}^{w}+S_{t}^{w}\right] \\
C_{t}^{r}=\xi_{t}\left[R_{t} \lambda_{t-1} A_{t-1}+H_{t}^{r}+S_{t}^{r}\right] \\
H_{t}^{w}=\left(1-\tau_{t}\right) W_{t} L_{t}^{w}+\frac{\omega H_{t+1}^{w}}{\left(1+n_{t+1}\right) \Omega_{t+1} R_{t+1}}+\frac{(1-\omega) H_{t+1}^{r}}{\left(1+n_{t+1}\right) \Omega_{t+1} R_{t+1} \psi_{t+1}} \\
H_{t}^{r}=\theta W_{t} L_{t}^{r}+\frac{\gamma H_{t+1}^{r} \psi_{t}}{R_{t+1} \psi_{t+1}} \\
S_{t}^{r}=N_{t}^{r} B W_{t}+\frac{\gamma S_{t+1}^{r} \psi_{t}}{\left(1+n_{t+1}\right) R_{t+1} t+1} \\
S_{t}^{w}=\frac{(1-\omega) N_{t}^{w} S_{t+1}^{r}}{N_{t+1}^{r} \Omega_{t+1} R_{t+1}} \frac{\xi_{t+1}}{\pi_{t+1}}+\frac{\omega S_{t+1}^{w}}{\Omega_{t+1} R_{t+1}\left(1+n_{t+1}\right)} \\
A_{t}\left(\frac{\lambda_{t}}{\omega}-\frac{1-\omega}{\omega}\right)=R_{t} \lambda_{t-1} A_{t-1}+\theta W_{t} L_{t}^{r}-C_{t}^{r}+N_{t}^{r} B W_{t}
\end{gathered}
$$

The equations for $\pi_{t}$ and $\xi_{t}, K_{t}, R_{t}, W_{t}, X_{t}, \Psi_{t}, N_{t}^{w}, n_{t+1}$ and $Y_{t}$ are same as the previous section.

The Production side of the economy did not change. We can therefore proceed to define the Competitive equilibrium in the PAYGO system

\subsection{Definition of Competitive Equilibrium}

A competitive equilibrium in the PAYGO system is a sequence of endogenous predetermined variables $\left\{K_{t-1}, A_{t-1}^{r}, A_{t-1}^{w}\right\}$ and a sequence of endogenous variables $\left\{\begin{array}{c}\pi_{t}, \xi_{t}, \Omega_{t}, H_{t}^{r}, H_{t}^{w}, C_{t}^{w}, L_{t}^{r}, L_{t}^{w}, \\ C_{t}^{r}, W_{t}, R_{t}, A_{t}^{w}, A_{t}^{r}\end{array}\right\}$, that satisfy equations 76-85 given the sequence of the exogenous predetermined variables $\left\{N_{t+1}\right.$, $\left.X_{t+1}\right\}$ specified by (6) and (59) and a given exogenous rate of payroll tax $\tau$, and given the initial values of all the predetermined variables, $\mathrm{K}_{t}, \mathrm{~A}_{t}, \mathrm{~N}_{t}$, and $\mathrm{X}_{t}$.

\section{Model with PAYGO-Defined Contribution Social Security Sys-}

\section{tem}

The PAYGO-Defined Contribution will be identical to the Defined benefit system except for the fact that now the contribution will be fixed. Following $\operatorname{Bohn}(2002)$ again,the government uses pension benefit financed by a fixed payroll tax on the current workers. Taxes and Benefits are conveniently stated in terms of a fixed payroll tax rate $\tau$ and a variable replacement rate $B_{t}$. Denoting $\tau W_{t} L_{t}^{w}$ real value of aggregate tax revenue from the worker and $E_{t}^{r}=N_{t}^{r} B_{t} W_{t}$ to be the real value of aggregate social security payment to the retiree, the government budget constraint looks like

$$
N_{t}^{r} B_{t} W_{t}=\tau W_{t} L_{t}^{w}
$$

The optimization will be identical to the defined benefit case, including the Ponzi contraints and the intertemporal budget constraints. Most of the aggregate relationships will remain unchanged. The ones that will changed are summarized as follows: 


$$
\begin{gathered}
L_{t}^{w}=N_{t}^{w}-\frac{\mu}{\left(1-\tau_{t}\right) W_{t}} C_{t}^{w} \\
H_{t}^{w}=(1-\tau) W_{t} L_{t}^{w}+\frac{\omega H_{t+1}^{w}}{\left(1+n_{t+1}\right) \Omega_{t+1} R_{t+1}}+\frac{(1-\omega) H_{t+1}^{r}}{\left(1+n_{t+1}\right) \Omega_{t+1} R_{t+1} \psi_{t+1}} \\
S_{t}^{r}=N_{t}^{r} B_{t} W_{t}+\frac{\gamma S_{t+1}^{r} \psi_{t}}{\left(1+n_{t+1}\right) R_{t+1} t+1} \\
A_{t}\left(\frac{\lambda_{t}}{\omega}-\frac{1-\omega}{\omega}\right)=R_{t} \lambda_{t-1} A_{t-1}+\theta W_{t} L_{t}^{r}-C_{t}^{r}+N_{t}^{r} B_{t} W_{t}
\end{gathered}
$$

The definition of competitive equilibrium will be identical to the defined benefit case where the above new equations has to be satisfied in equilibrium.

\section{Model with Fully Funded-Defined Benefit Social Security}

In the Fully Funded(FF from now on) defined benefit model we will consider optimization where there is a FF social security system for the retiree. This system is different from the PAYGO system in a number of ways. First, under the FF system, a worker pays payroll tax throughout his working life. Second, this tax revenue is put into a fund where the government invests the proceeds(social security fund). Finally, when the person retires, he receives social security which would be the tax revenue he accumulated plus the interest. For simplicity, we will assume the worker pays a payroll tax $\tau_{t}$. The retirees again will not be taxed. When the worker moves into the retirement phase, he will receive the accumulated tax revenue plus interest. Making retirement benefit contigent on the life long tax payments throughout working phase is the correct mechanism. But it is very complicated, we will assume that the retirees benefit is linked to the taxes paid right before retirement. In this way, the fully funded defined benefit(DB) system will be a notional fully funded system where the financing formula uses a Bismarckian Rule ${ }^{5}$, where the pensions are related to the partial earnings history, in our case, the history just before retirement.

\subsection{Optimization by the Retiree}

The optimization problem by the retiree looks very similar to the PAYGO Defined Benefit case, including the Ponzi contraints and the intertemporal budget constraints, except for the fact that the retirees' social security now depends on the tax collected from the workers previously. For a retiree at $t$ who participates in a perfect annuities market, he chooses $C^{r j k}, l^{r j k}$ to maximize (57) subject to the (58). The first order conditions are same as (59) and (60).

Similar to the PAYGO case, I guess that the consumption function looks like:

$$
C_{t}^{r j k}=\xi_{t}\left(\frac{R_{t} A_{t-1}^{r j k}}{\gamma}+H_{t}^{r j k}+S_{t}^{r j k}\right)
$$

$\xi_{t}, A_{t-1}^{r}, H_{t}^{r}$ has been defined before and $S_{t}^{r j k}$ is the expected lifetime social security payment which, although defined before, is given by:

\footnotetext{
${ }^{5}$ For an elaborate discussion on the Bismarckian rule and other financing rule such as the Beveridgean Rule, see Docquier and Paddison(2003)
} 


$$
S_{t}^{r j k}=\sum_{v=0}^{\infty} \frac{\frac{\gamma^{v} E_{t+v}^{r}}{N_{t+v}^{r}}}{\prod_{z=0}^{v} R_{t+z+1}}=\frac{E_{t}^{r}}{N_{t}^{r}}+\frac{\gamma S_{t+1}^{r j k}}{R_{t+1}}
$$

Where $E_{t+v}^{r}=N_{t+v}^{r} B W_{t+v}$ is the aggregate social security payments that all the retirees in period $t$ receives. We will also have similar guess for the $V_{t}^{r}$ as (63) and condition (89) has to be satisfied. The MPC of the retirees will also follows the same law of motion as the equation (65)

\subsection{Optimization by the Worker}

The worker's problem would also be similar except now he has to pay a payroll tax on his wage income. We will assume that the worker pays a constant payroll tax $\tau_{t}$ on his wage income. The worker's will choose $C_{t}^{w j k}, l_{t}^{w j k}$ to maximize (66) subject to (67) and (68). We will again guess identical function for the consumption function as the PAYGO-DB. All the variables have the same functional form. The law of motion for $\pi_{t}$ is identical as the PAYGO-DB case. We will have similar guess about the functional form for $V_{t}^{w j k}$. The first order condition with respect to $C_{t}^{w j k}$ and $l_{t}^{w j k}$ yields identical solutions as the PAYGO-DB case.

\subsection{Derivation of Aggregate Functions}

Just like the PAYGO-DB system, in the case of the FF-DB system, there will be an additional aggregate constraint, the government budget. The government distribute social security payment among the retirees which will be collected as payroll tax from the workers from the previous period. Following Abel(2003) and Karni and Zilcha(1989), denoting $\tau_{t} W_{t-1} L_{t-1}^{w}$ aggregate tax revenue from the worker from period $t-1$ and $N_{t}^{r} B W_{t}$ to be the aggregate social security payment to the retiree, the Government Budget constraint looks like

$$
N_{t}^{r} B W_{t}=\left(\tau_{t} W_{t-1} L_{t-1}^{w}\right) R_{t}
$$

The capital market clearing condition now looks like:

$$
K_{t}=A_{t}^{r}+A_{t}^{w}+\tau_{t} W_{t} L_{t}^{w} \forall t
$$

The rest of the aggregate relationships are identical to equations (77)-(85).

\subsection{Definition of Competitive Equilibrium}

A competitive equilibrium in the FF-DB will be same as the PAYGO-DB where all the previous conditions have to be satisfied and also equation 93 and 94 are satisfied.

\section{Model with Fully Funded-Defined Contribution Social Secu- rity}

The FF-DC will be identical to the DB system except for the fact that now the contribution will be fixed. Following Karni and Zilcha(1989) again,the FF-DC budget constraint looks like:

$$
N_{t}^{r} B_{t} W_{t}=\left(\tau W_{t-1} L_{t-1}^{w}\right) R_{t}
$$

All other aggregate relationships will remain unchanged except some whose form will look like the new set of equations defined in case of the PAYGO-DC case. 


\section{Calibration and nature of experiments under different pension}

\section{systems}

There are two sources of growth in this economy, the population growth and the technological progress. Thus in steady state all the quantity variables grow at the exogenously given rate of growth of the effective labor force, $X_{t} L_{t}^{w}$, which is equal to $(1+x)(1+n) \approx(1+x+n)$. Because there is growth in the steady state, we have normalize each of the choice variables. For $Y_{t}, H_{t}^{r}, H_{t}^{w}, C_{t}^{w}, C_{t}^{r}, L_{t}^{w}, L_{t}^{r}, L_{t}$ and $K_{t-1}$, we use $X_{t} N_{t}^{w}$ and for $W_{t}$ we use $X_{t}$ as the scaling factor. Appendix 1,2 and 3 shows the derivation, scaling and the steady state system for the private annuity market without social security. The rest of the models are derived in the similar manner.

Table 1 shows calibrated values of the exogenous parameters used in this paper. The calibration of each of the models is very crucial. It is therefore important to specify the calibration strategy very clearly. First, PAYGO-DB will serve as the baseline model for this paper because it is the system that operates in existence. In order to calibrate the model to derive steady state values of our choice variables, I will choose values for the exogenous parameters $\beta, \alpha, \gamma, \delta, \theta, \omega, \mu, \nu, x, n$ and $\sigma$.The value of $\gamma$ and $\omega$ are taken from Auerbach and Kotilikoff(1987). They are chosen so that a person spends 45 years as worker and 10 years as retired.Following Ferrero(2005), individuals are assumed to enter the workforce as workers when they are 20 years old and work on average $(1-\omega)^{-1}$ years. The value of the parameter $\omega=0.977$ is chosen to match a 45 -year average permanence in the labor force, which corresponds to Auerbach and Kotilikoff(1987), where the calibration is done as follows:

$$
(1-\omega)^{-1}=45 \Rightarrow \omega=\frac{44}{45}=0.977
$$

The value of the survival probability of a retiree, $\gamma$ is chosen to be 0.80 to match the average expected lifetime horizon for a retiree, which is equal to 70 years for the US and EU. The formula works as follows:

$$
65+(1-\gamma)^{-1}=70 \Rightarrow \gamma=\frac{4}{5}=0.80
$$

Therefore, we use the above mentioned values for the choice parameters. The value of $\nu$ and $\theta$ is taken from Cooley(1995). The rest of the variables are taken from Campbell(1994) but can also be found in Rebelo and King(1988). The value of $\sigma$ and $\beta$ are the most crucial and controversial parameters of the model. I will calibrate them simultaneously along with two other important variables of the model, the social security tax and the replacement rate, or the benefit rate. The choice of using appropriate value for the social security tax and the benefit rule is very important. Bohn(2002) uses the value of $\tau$ to be $12.4 \%$ and value of the benefit rate to be be in between $30 \%$ and $40 \%$. But unlike him, I have more restriction in my calibration because I have to also match the real interest rate for the economy which should be very close to $3 \%$. I will choose a plausible value for $\tau$ so that I get a plausible value for the participation rate. In case of the PAYGO-DB, I will choose $\sigma$ and $\beta$ to be 0.50 and 0.96 and the participation rate to be $24.9 \%$. The system of nonlinear equations in the steady state then will yield a steady state tax rate to be equal to $12.4 \%$ which matches with $\operatorname{Bohn}(2002)^{6}$. These two values will serve as the benchmark values. In case of the DB systems, we will keep the participation rate constant at $24.9 \%$ and determine the tax rate. In case of the DC systems, we will keep the tax rate constant

\footnotetext{
${ }^{6}$ Trying to calibrate the value of participation rate to be equal to $30 \%$ and tax rate to be $12.4 \%$ and achieve a real interest rate to be close to $3 \%$ was a difficult task and will consider values of $\beta$ and $\sigma$ which are usually used in the literature. I will therefore, only use plausible values of them . This will give a real interest rate which is close to $3 \%$, a tax rate which is $12.4 \%$ and a benefit rate which is close to $30 \%$.
} 
at $12.4 \%$ and will determine the participation rate. As we will show, in order to get tax rate and participation rate under the FF system similar to the the PAYGO, we will assume the value of $\beta$ to be 0.958 instead of 0.96 . For the Private Annuity market, I will use the baseline parameter from the PAYGO-DB system. Table-1 reports all the parameter values to be used in the model.

Now the nature of the experiment that I will conduct has to be specified clearly. My experiment will look at the impulse response functions and transitional dynamics of the systems when there is an unanticipated permanent $1 \%$ increase in the growth rate of workforce. I will use Gensys algorithm to derive my impulse response functions. My methodology to derive impulse

response of a permanent shock will follow Leeper and $\operatorname{Yang}(2006)$. Define $\hat{Z}_{t}=\log \left(\frac{\tilde{Z}_{t}}{\widetilde{Z}}\right)$ to be the $\log$ deviation of a variable from its balanced growth trajectories. We then log-linearize the entire system of equations and feed in to the Gensys algorithm developed by Sims(2002). After identifying that the systems have a unique solution,I proceed to derive the impulse response functions of the choice variables for a one percent permanent shock to the growth rate of the workforce. The derivation is done in two steps. First, Gensys calculates the initial response of the variables to the population shock. Next, I iterate on the initial response for 100 periods and derive the impulse response functions of the variables in the system.

\section{Comparison of Performance under different Social security}

Our economic analysis of the economy under alternative pensions systems will be done in six steps. First, we will look at performance of the economy under initial steady state of the system when the population is stationary. Second, we will look at the immediate response of the economy of a permanent population shock. Third, we will look at the dynamics of the economy during the transition to the new steady state. Fourth, we will compare the economy under initial and new steady state. Fifth, we will compare the social welfare of the economy before and after the permanent population shock. Finally, we will simulate our model and compare the volatility of the fundamental variables of our model under different social security regime when there is a population shock.

\subsection{Analysis of Initial Steady State}

Table 2 reports the steady state values of the variables of each of the systems before and after a permanent shock. We see several interesting results. First, In the initial steady state, the MPC for the retiree is significantly larger than the MPC for the workers under alternative systems. Lower MPC for the worker is a desirable property of my life-cycle model because it is consistent with the classic lifecycle model predictions of Modigliani(1956) and Harrod(1948). Therefore, the model passes the first acid test because it mimics life-cycle consumption propensity. Second, The initial steady state capital is also largest for the perfect annuity model. The PAYGO system has higher capital than the FF system. The initial steady state capital is also higher under PAYGO for both the worker and the retiree. Third, Overall, the retirees supply little labor compared to the workers. In the initial steady state,total labor supply is the largest for the perfect annuity model. Worker's labor supply is lowest under FF system. Retiree's labor supply is similar under PAYGO or FF and lower than perfect annuity market. According to Feldstein(2005), a perfect annuity market with no social security will surely yield higher capital accumulation when there is stationary population. This is because social security involves some form of taxation(either fixed or flexible) which distorts savings by the worker. This is evident by a $17 \%$ decline in initial steady state savings(comparing row 9 , column 2 and column 5 of table 2 ) by the worker under 
PAYGO and a $21 \%$ decline in case of FF(comparing row 9, column 2 and column 8 of table 2). Again, social security benefits(defined or flexible) distorts savings by the retiree which was highlighted by Bohn(2002). The disincentive of the retiree to save more results in a $56 \%$ reduction in savings under PAYGO and a $62 \%$ decline in case of FF. Overall, there is a $11 \%$ decline in total savings under PAYGO and $15 \%$ decline under FF. These are much lower compared to a 30-50\% reduction estimated by Feldstein(1974). But the puzzling fact is that FF yields lower savings than PAYGO. A closer analysis should resolve this issue. First, notice that the nature of income inequality is identical under PAYGO and FF in the initial steady state. Second, retirees labor supply under these two regimes are almost identical. Hence, total labor supply decline because of the decline in worker's labor supply. With a slightly higher wage in the PAYGO systems, the retirees enjoy higher labor income than FF. Although rental rate is slightly lower under the PAYGO, the workers with much bigger chunk of capital earns a higher capital income than the retirees. Finally, since the social security benefit is same under PAYGO and FF in the initial steady state(as was the objective of my calibration exercise), the retirees, overall, has lower income under FF than under PAYGO. Therefore, PAYGO with higher income for both workers and retirees results in a higher capital accumulation in PAYGO than FF. From the risk sharing perspective of the social security systems, we notice one striking result. In an economy where the retirees work part time, an Intergenerational risk sharing mechanism like the FF systems fail to outperform an Intergenerational risk sharing mechanism like the PAYGO. The above analysis suggests that the distortion created by social security has been dominated by a combination of favorable rental rate and an unfavorable wage rate movement. Bohn(1998) argues that this is

only possible when $\frac{\tau}{1-\tau}$ is below the capital and labor share of the output. In our PAYGO and FF models, the former is 0.1415 where the later two are 0.333 and 0.667 respectively. Again since the capital-share of output dominates labor share, interest rate movement dominates the wage rate movement effect. Finally, The initial steady state output is the largest for the perfect annuity model. The PAYGO systems have higher output than the FF systems. The first part of the observation is consistent with other works on life-cycle models like Feldstein(1974) and Feldstein(2005) which argue that a fully efficient perfect annuity market creates no additional distortion in the economy and therefore, should yield higher output. The better performance of the PAYGO models follow from the superior performance of the former in terms of capital accumulation and inducing slightly higher labor supply than the FF model.

\subsection{Analysis of Immediate Impact of a Permanent Population Shock}

Table 3 reports the immediate response of each of the systems after a permanent population shock. The responses are presented in log deviating terms from the initial balanced growth trajectories, which in terms of our scaled variable models, a log-deviation from the initial steady state. We notice some interesting aspects of the immediate responses. First, Consumption of both worker and retiree responds positively to the population growth shock. The response is largest under the private annuity model. DC systems offer better response to consumption. Second, PAYGO-DB seems to share consumption risk across the workers and the retirees better than any other social security arrangements. The private annuity market has the worst risk sharing performance. Third, capital shows consistent decline across all models. The rate of decline is the smallest under PAYGO-DB. Workers savings shows slower decline than the retirees. Retirees savings decline faster under the DC systems, specially under the FF. Fourth,Output response is smallest under the PAYGO-DC. Fifth, total labor supply declines immediately across all regimes. Workers increase their labor supply under the DB systems and decrease under DC. The retirees dramatically decreases their labor supply consistently across different regimes. Sixth, upon impact, decline in output is smallest under FF-DB. Seventh,upon impact, decline in capital is the smallest under the DB systems. Eighth, upon impact, the absolute difference between the 
response of the workers and the retirees are the smallest under FF-DB, then under PAYGO-DB. The difference is largest under the Private Insurance model. Finally, impact on wage is positive across all regimes. Impact on real interest rate is positive only under the DB systems.

Although analyzing risk sharing behavior is not the main purpose of this paper, this is indeed a very interesting results which needs some explanations. Bohn(2002) argues that population risk are not naturally shared by different cohorts. Population growth raises the marginal product of capital and while it reduces the marginal product of labor. Government policy can allocate this risk by appropriate transfers and taxes. We see this result in our model too. Measuring risk sharing by looking at the absolute difference between the immediate response of consumption for the workers and the retirees ${ }^{7}$ (row 4 , table 6 ), we see that the private annuity market clearly fails to share risk associated with the population shock in Bohn's sense. Similar to Bohn, PAYGO-DB outperforms all other social security arrangement.

An analysis of the causes behind the above mentioned results are crucial for understanding the entire dynamical response of our model to population shock under different regimes. We will adopt a blend of RBC and public finance approach to explain the immediate response of our models. Combining Rebelo and King(2002) and Bohn(1998), we will decompose the effect of population shock into wage effect and interest effect and the social security effect. In case of the PAYGO-DB, we will start with the social security effect. An increase in the number of worker reduces the dependency ratio, which with a DB system, reduces payroll tax(table 3, row 21 and 22). This results in a decline of the total benefit to the retirees, although the benefit rule is fixed(table 3, row 21 and 23). The social security effect is therefore a negative income effect to the retiree and a positive income effect on the worker. With almost no to very small decline in the real interest rate,retirees savings go down. The wage effect of the population is very strange. There is a an immediate reduction of labor supply by the worker and the retiree. We therefore see a slight increase in the wage rate. The running down of savings and the decline labor supply also justifies the immediate increase in consumption for both the worker and the retiree. The PAYGO-DB shares similar dynamics with the FF-DB. With PAYGO-DC, however, there is a small visible decline in the real interest rate with larger increase in wage. The decline is labor supply is now larger a which coupled with a larger decline now reduces output at a higher rate. The FF-DC exhibits similar behavior as the PAYGO-DC.

\subsection{Analysis of the Transition Path after a Permanent Population Shock}

Figure 6-9 shows the impulse response of the major aggregate variables in my model after a permanent shock. Since the impulse response functions show log deviations of the variables from their balanced growth trajectories, they are not convenient to analyze the changes in the level of the variables during the transition. I therefore report transitional dynamics of the variables in levels(each variables are scaled) in figures 10-15. The transitional dynamics will also analyzed by using wage rate, interest rate effect and the social security effect.

In case of the PAYGO-DB, wage goes down, real interest rate goes up and social security tax goes down in the transition. For the worker, he faces a combination of negative wage raterelated income effect, positive interest rate-related income effect and a positive payroll tax-related income effect. The negative effects dominate at the beginning and we see an increase in labor supply. After that and we see a steady decline of consumption, savings and labor supply. For

\footnotetext{
${ }^{7}$ Bohn(2002) argues that for standard time-separable homothetic preferences, ex-ante efficiency has strong implication: the consumption of workers and retirees should be equally exposed to population shocks. He uses The Method of Undeterminant Coefficients follwing King and Rebelo(1998) to calculate the elasticity coefficient of consumption for population shock. This is similar to looking at the difference between the immediate impact reponse of consumption in our model. The smaller the absolute difference between the impact response of consumption by the retiree and the worker, the better is the risk sharing.
} 
the retiree, his social security effect is negative, because total benefit falls. For him, negative effects now dominate and we see gradual increase in labor supply, decline in consumption and savings. The overall effect on capital accumulation is quite negative and the effect on total labor supply is slightly positive during the transition path. We therefore see a slow decline in the output. Therefore, PAYG0-DB social security distorts output, savings, consumption smoothing and forces retirees to work more.

In case of the PAYGO-DC, the retirees now receive larger total benefit because the benefit rate goes up. But the negative wage effect clearly dominates and we see similar increase labor supply as with the PAYGO-DB. But favorable movement of the benefit and interest rate allows them to decrease saving slowly. On the other hand, a decline in wage coupled with a fixed tax rate implies a larger tax burden on the worker. His after tax wage is smaller. This results in a rapid de-accumulation of savings along with a slight decline in the labor supply. The ultimate outcome is again a decline in capital and output.

In case of the FF-DB, a decline in the tax rate results in a decline in the total benefit for the retiree. This and the decline in wage triggers a melt down of savings for the retiree along with an increase in the labor supply. The negative wage effect for the worker cannot be compensated by the reduction in tax rate. Hence we see a similar decline in savings and a small decline in labour supply. The final outcome is a decline in output and savings.

In case of the FF-DC, the effect on the worker mimics PAYG0-DC. But for retiree, the increase in total benefit enables them to de-accumulate savings slower than FF-DB. But this time, worker dominates and wee see a slightly decline in output and capital.

The private annuity model is also quite interesting. Without social security, retiree now works more, saves much less. The worker on the other hand, does not face any tax distortion. This allows him to de-accumulate his savings slowly, consume more compared to rest of the regimes and increase the supply of labor. All this results in output and capital levels along transition path which are visibly higher than any other social security regime.

In summary, the transition dynamics is determined by the combination of wage, interest rate and social security effect. In these experiments, wage effect will dominate the interest rate effect. With PAYGO-DB, the negative wage effect slightly overcomes positive real interest rate and tax effect for the worker. For the retiree, negative wage and total benefit effect clearly outweighs the positive real interest rate effect. In case of PAYGO-DC, the increase in the total benefit has a positive effect on retirees income which creates larger distortion in savings and labour supply decision. As a result, we end up with slightly lower output in the new steady state than the PAYGO-DB. The FF-DB adds to the woes of the retirees by decreasing their benefit. The result is a lower accumulation of capital and hence, output compared to the PAYGO-DB case. Finally, FF-DC performs the worst because the negative wage effect is the largest and the increase in the real interest rate causes largest decline in their lifetime labour income and lifetime social security. The result is the lowest accumulation of capital and hence, lowest output. None of the social security distortion is present in the private annuity market. Hence it performs the best in terms of capital accumulation and output.

\subsection{Comparison Between Initial and New Steady State}

Table 2 shows a comparison between initial steady state and the new one. The dynamic responses of the system is not fundamentally different across regime. A worker population growth rate worsens economic conditions in all the regimes, consumption, output and savings all go down. Private annuity market performs better than any other social security regime in absorbing the shock. The surprising result is that PAYGO-DB outperforms all other social security regime just like it did in the initial steady state. Critical analysis of the transition path has pointed out the reason behind its success. 


\subsection{Welfare Comparison Under Various Pension Regimes}

Table 4 reports steady state welfare comparison under different pension system. Appendix 4 explains how the social welfare is calculated for each of the pension systems. I report three different measure of steady state welfare. $V^{r}$ represents the welfare of the retiree and $V^{w}$ represents the welfare of the worker. Finally, $V$ represents the aggregate social welfare which is a population weighted average of $V^{r}$ and $V^{w}$. Comparing welfare between workers and the retirees across different pension systems reveal interesting differences. First, retirees welfare is the same under

PAYGO and FF in the initial steady state. They enjoy higher welfare under FF in the final steady state. Second, workers receive higher welfare under FF during the initial and also the final steady state. Third,social welfare is maximized under FF both in the initial as well as in the final steady state. Fourth, there appears to be a clear trade-off between growth and welfare. The above results in terms of welfare are consistent with Karni and Zilcha(1989), Feldstein(2005) and abel(2003).So there is no need to provide any intuition about this result. What is interesting is that FF systems raise welfare but reduce savings compared to the PAYGO system. This indicates that when there is a work force growth and when the retirees work part time, a PAYGO system would be preferable on the savings and growth grounds. But on the welfare grounds, FF is still the winner

\subsection{Volatility of the Economy under various Social Security Regimes}

The volatility of the system depends on the speed of convergence of the system. Since population shock is a negative shock to the system, the existence of some risk sharing mechanism will allow the economy to converge slower and should also reduce the volatility of the system. Table 5 reports the speed of convergence of the economy under different social security regime. Without going into the analysis of individual variables, we see that PAYGO, offering a better risk sharing mechanism, also helps the economy converge slower than any other arrangement. Private annuity market help the economy converge faster than any other system in general. This is reflected in the volatility of the system. Table 6 reports the volatility of consumption, output and capital under various social security arrangements ${ }^{8}$. It appears that the economy the economy much more volatile under the private annuity market. FF-DB provides us with the least volatile economy. Bohn(1998) argues that a system that has the least risk sharing structure would be subject to most volatility. This is evident in our experiments as well. It is therefore not surprising to find that the volatility under PAYGO and FF are comparable because they have some risk sharing mechanism.

\section{Conclusion}

In this paper, a serious attempt has been undertaken to model lifecycle demographic uncertainty into a DSGE framework. An attempt has been made to use tools and experimental setup that are traditionally been used in the RBC literature. With more rigorous and realistic design of the social security, this setup can be used very effectively without resorting to non-tractable large

\footnotetext{
${ }^{8}$ In order to simulate the economy under alternative social security systems, I first draw 10000 observation on the error term for the populattion growth eqution from a normal distribution with zero mean and very small variance of 0.00007259 . I do this once. I then take the log-linearized system of equations, convert them into levels and simulate each of the models.
} 
scale OLG models. The model however has generated some interesting analytical results, some of which clearly contradicts existing steady state based results, even some large scale modeling attempt with stationary population. The paper, however, has several limitations which has to be stated precisely. First, allowing retirees to work but not subjecting them to payroll tax is very unrealistic. One could get different results if the latter is allowed. Second, the calibration exercise plays an important role in deriving the results of the model. The calibration exercise is not entirely satisfactory because most of the target variables were not calibrated to match data exactly. But the most serious criticism of the paper is the nature of the experiments that has been undertaken. In case of $\mathrm{DB}$, it is assumed that only the benefit rate is constant while in the DC case, only the tax rate is assume to be constant. Neither of the assumptions are correct and they do not resemblance the reality. Although the existing literature follows my strategy, the correct experiment would to keep the total benefit constant in the DB case and keep total tax revenue constant under the DC case. We can then have a common ground on which we can evaluate the efficacy of each of the social security arrangements. Without such a design, what we have done is to work with notional DB and DC system and therefore, the policy implications of the above experiments have been undermined. In order to verify quantitative precision of the model predictions, one has to be more careful with the calibration strategy. If it is done, and if the conclusion of this exercise survives the test, then we have made significant contribution to the debate over demographic uncertainty and its effect on social security design and on the economy in general

\section{References}

[1] Abel, Andrew, B.,(2003). The Effects of a Baby Boom on Stock Prices and Capital Accumulation in the Presence of Social Security. Econometrica, 71, 2 (March 2003), 551-578.

[2] Auerbach, A.J. and Kotlikoff, L., (1987). Dynamic Fiscal Policy, Cambridge University Press, Cambridge.

[3] Blanchard, O.J., (1985). Debt, Deficits and Finite Horizons. Journal of Political Economy, 93 (April): 223-247.

[4] Bohn, Henning,(2002). Retirement Savings in an Aging Society: A case for Innovative Government Debt Management. Department of Economics, University of California at Santa Barbara

[5] Bohn, Henning,(1999). Social Security and Demographic Uncertainty: The Risk Sharing Properties of Alternative Policies. Department of Economics, University of California at Santa Barbara

[6] Bohn, Henning,(1998). Risk Sharing in a Stochastic Overlapping Generations Economy. Department of Economics, University of California at Santa Barbara

[7] Cass, D., (1965). Optimum Growth in an Aggregate Model of Capital Accumulation. Review of Economic Studies, 32 (July): 233-40.

[8] Clarida, R.H., (1991). Aggregate Stochastic Implications of the Life-Cycle Hypothesis. Quarterly Journal of Economics, 106 (August): 851-868.

[9] DeNardi, M., imrohoroglu, S., and Sargent, T.J., (1998). Projected U.S. Demographics and Social Security, mimeo, Stanford University. 
[10] Diamond, P.A., (1965). National Debt in a Neoclassical Growth Model. American Economic Review, 55 (December): 1126-50.

[11] Docquier, Fredric, Paddison,Oliver.,(2003). Social Security benefit rules, growth and inequality. Journal of Macroeconomics, Vol:25(47-71).

[12] Farmer, R. E.: 1990, Rince preferences, Quarterly Journal of Economics 105, 43-60.

[13] Feldstein, Martin.,(1974).Social Security, Induced Retirement and Aggregate Capital Accumulation. Journal of Political Economy, Vol. 82, No. 5, September-October 1974.

[14] Feldstein, Martin.,(2005)."Rethinking Social Insurance," The 2005 Presidential Address to the American Economic Association. American Economic Review, March 2005.

[15] Gertler, M.: 1999, Government debt and social security in a life-cycle economy, CarnegieRochester Conference Series of Public Policy 50(1), 61-110.

[16] Gertler, M.: (2000), Infinite Horizon Consumption-Savings Decision under Uncertainty, Department of Economics, New york University, Fall 2000. Link: http://www.econ.nyu.edu/user/cavallom/macro_1/lect_3.pdf

[17] Gali, J., (1990). Finite Horizons, Life-Cycle Saving and Time Series Evidence on Consumption. Journal of Monetary Economics, 90: 433-452.

[18] King, Robert, G., and Rebelo, Sergio, T.,(2000). Resuscitating Real Business Cycles. National Bureau of Economic Research, Working Paper 7534. Cambridge, MA

[19] Hubbard, R.G. and Judd, K.L., (1987). Social Security and Welfare. American Economic Review, 77 (September): 630- 646.

[20] Karni, Edi., and Zilcha, Itzhak.,(1989). Aggregate and Distributional Effects of Fair Social Security, Journal of Public Economics, 40(37-56)

[21] Keuschnigg, C. and Keuschnigg, M.: 2004, Aging, labor markets and pension re- form in Austria, University of St. Gallen Department of Economics working paper series 2004-03.

[22] Kilponen, J. and Ripatti, A.: 2006, Labour and product market competition in a small open economy - simulation results using a DGE model of the ... Finnish economy, Bank of Finland Discussion Papers 5/2006

[23] Koopmans, T.C., (1965). On the Concept of Optimal Economic Growth. The Econometric Approach to Development Planning. North Holland, Amsterdam.

[24] Leeper, Eric, M., and Yang, Susan, Shu-Chun.,(2007). Dynamic Scoring: Alternative Financing Schemes. Journal of Public Economics, Forthcoming

[25] Maestas, N. (2004). Back to work: Expectations and realizations of work after retirement. (RandWorking Paper WR-196). Retrieved July 29, 2005 from http://www.rand.org/publications/WR/WR196/

[26] Modigliani, F., (1966). The Life-Cycle Hypothesis of Saving, the Demand for Wealth and the Supply of Capital. Social Research, 33 (June): 160-217.

[27] Cahill, Kevin, E., Giandrea, Michaeal, D., and Quinn, Joseph, F.,(2005). Are Traditional Retirements a Thing of the Past? New Evidence on Retirement Patterns and Bridge Jobs. US department of Labour, Bureau of Labour Statistics, Workig paper 384. 
[28] Romer, D., (1989). What Are the Costs of Excessive Deficits? NBER Macroeconomics Annual: 63-98.

[29] Tobin, J., (1967). Life-Cycle Saving and Balanced Growth. Ten Economic Studies in the Tradition of Irving Fisher. Wiley, New York.

[30] Weil, P., (1990). Nonexpected Utility in Macroeconomics. Quarterly Journal of Economics, 105 (February): 29-42.

[31] Weil, P.: 1989, Overlapping families of infinitely-lived agents, Journal of Public Economics $38,183-198$.

[32] Yaari, M. E.: 1965, Uncertain lifetime, life insurance and the theory of consumer, Review of Economic Studies 32, 137-150. 


\section{Appendix 1: Solving the Private Annuity model without government}

Retirees Problem

The retirees solve the following problem:

$$
\begin{aligned}
& V_{t}^{r j k}\left(A_{t-1}^{r}\right)=\left\{\left[\left(C_{t}^{r j k}\right)^{v}\left(1-l_{t}^{r j k}\right)^{1-v}\right]^{\rho}+\beta \gamma\left[V_{t+1}^{r}\left(A_{t}^{r}\right)\right]^{\rho}\right\}^{\frac{1}{\rho}} \\
& \left\{C^{r j k}, l^{r j k}\right\}
\end{aligned}
$$

Subject to:

$$
A_{t}^{r j k}=\frac{R_{t} A_{t-1}^{r j k}}{\gamma}+W_{t} \theta l_{t}^{r j k}-C_{t}^{r j k}
$$

With $0 \prec \theta \prec 1$.

The first order condition with respect to $C^{r j k}$ look like:

$$
\begin{aligned}
& \frac{1}{\rho}\left\{\left[\left(C_{t}^{r j k}\right)^{v}\left(1-l_{t}^{r j k}\right)^{1-v}\right]^{\rho}+\beta \gamma\left[V_{t+1}^{r}\left(A_{t}^{r}\right)\right]^{\rho}\right\}^{\frac{1}{\rho}-1}
\end{aligned}
$$

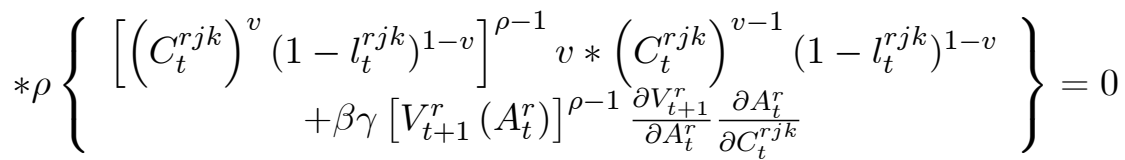

Envelope condition:

$$
\begin{aligned}
& \frac{\partial V_{t}^{r}}{\partial A_{t-1}^{r}}\left|\quad C_{t}^{r j k}=C_{t}^{*}\left(A_{t-1}^{r}\right)=\frac{\partial U\left(C_{t}^{r j k}, l_{t}^{r j k}\right)}{\partial A_{t-1}^{r}}\right|_{C_{t}^{r j k}=C_{t}^{*}\left(A_{t-1}^{r}\right)} \\
&=\quad \rho\left[\left(C_{t}^{r j k}\right)^{v}\left(1-l_{t}^{r j k}\right)^{1-v}\right]^{\rho-1} \\
& v *\left(C_{t}^{r j k}\right)^{v-1}\left(1-l_{t}^{r j k}\right)^{1-v} V_{t}^{r}\left(A_{t-1}^{r}\right)^{1-\rho} \frac{R_{t}}{\gamma}
\end{aligned}
$$

Substituting equation(d) into the first order condition yields after some simplification, the following Euler equation for $C_{t}^{r j k}$ :

$$
\left(C_{t}^{r j k}\right)^{v \rho-1}\left(1-l_{t}^{r j k}\right)^{\rho(1-v)}=\beta R_{t+1}\left(C_{t+1}^{r j k}\right)^{v \rho-1 v \rho-1}\left(1-l_{t+1}^{r j k}\right)^{\rho(1-v)}
$$

First order condition with respect to $l_{t}^{r j k}$ yields:

$$
\begin{aligned}
& \frac{1}{\rho}\left\{\left[\left(C_{t}^{r j k}\right)^{v}\left(1-l_{t}^{r j k}\right)^{1-v}\right]^{\rho}+\beta \gamma\left[V_{t+1}^{r}\left(A_{t}^{r}\right)\right]^{\rho}\right\}^{\frac{1}{\rho}-1} \\
& * \rho\left\{\begin{array}{c}
{\left[\left(C_{t}^{r j k}\right)^{v}\left(1-l_{t}^{r j k}\right)^{1-v}\right]^{\rho-1}(1-v)\left(C_{t}^{r j k}\right)^{v}\left(1-l_{t}^{r j k}\right)^{-v}(-)} \\
+\beta \gamma\left[V_{t+1}^{r}\left(A_{t}^{r}\right)\right]^{\rho-1} \frac{\partial V_{t+1}^{r}}{\partial A_{t}^{r}} \frac{\partial A_{t}^{r}}{\partial l_{t}^{r j k}}
\end{array}\right\}=0
\end{aligned}
$$

The envelope condition:

$$
\begin{aligned}
\frac{\partial V_{t}^{r}}{\partial A_{t-1}^{r}}\left|\quad l_{t}^{r j k}=l_{t}^{*}\left(A_{t-1}^{r}\right)=\frac{\partial U\left(C_{t}^{r j k}, l_{t}^{r j k}\right)}{\partial A_{t-1}^{r}}\right|_{l_{t}^{r j k}=l_{t}^{*}\left(A_{t-1}^{r}\right)} & \rho\left[\left(C_{t}^{r j k}\right)^{v}\left(1-l_{t}^{r j k}\right)^{1-v}\right]^{\rho-1} \\
& (1-v)\left(C_{t}^{r j k}\right)^{v}\left(1-l_{t}^{r j k}\right)^{-v} V_{t}^{r}\left(A_{t-1}^{r}\right)^{1-\rho} \frac{R_{t}}{W_{t} \theta \gamma}
\end{aligned}
$$


Now at the optimum, the envelope condition also suggests:

$$
\left.\frac{\partial V_{t}^{r}}{\partial A_{t-1}^{r}}\right|_{C_{t}^{r j k}=C_{t}^{*}\left(A_{t-1}^{r}\right)}=\left.\frac{\partial V_{t}^{r}}{\partial A_{t-1}^{r}}\right|_{l_{t}^{r j k}=l_{t}^{*}\left(A_{t-1}^{r}\right)}
$$

Therefore, equating (d) and (f) and after some simplification:

$$
l_{t}^{r j k}=1-\frac{\mu}{\theta W_{t}} C_{t}^{r j k}
$$

where:

$$
\mu=\frac{1-v}{v}
$$

Finally, substituting the first order condition for $l_{t}^{r j k}$ into Euler equation for $C_{t}^{r j k}$ (equation e) yields the following compact form of the Euler equation:

$$
C_{t+1}^{r j k}=\left[\left(\frac{W_{t+1}}{W_{t}}\right)^{\rho(1-v)}\left(\beta R_{t+1}\right)\right]^{\sigma} C_{t}^{r j k}
$$

Now guess that:

$$
C_{t}^{r j k}=\xi_{t}\left(\frac{R_{t} A_{t-1}^{r j k}}{\gamma}+H_{t}^{r j k}\right)
$$

where $H_{t}^{r j k}$ is defined by equation(19) in the main text. Also guess that the value function $V_{t}^{r j k}$ has the following form:

$$
V_{t}^{r j k}=\Delta_{t}^{r} C_{t}^{r j k}\left(\frac{\mu}{\theta W_{t}}\right)^{1-v}
$$

Plugging the guess for $V_{t}^{r j k}$ into the bellman equation for the retiree, we get:

$$
\left[\Delta_{t}^{r} C_{t}^{r j k}\left(\frac{\mu}{\theta W_{t}}\right)^{1-v}\right]^{\rho}=\left\{\left[\left(C_{t}^{r j k}\right)^{v}\left(1-l_{t}^{r j k}\right)^{1-v}\right]^{\rho}+\left[\beta \gamma \Delta_{t+1}^{r} C_{t+1}^{r j k}\left(\frac{\mu}{\theta W_{t+1}}\right)^{1-v}\right]^{\rho}\right\}
$$

After substituting the first order condition for $l_{t}^{r j k}$ and the Euler equation for $C_{t}^{r j k}$ on the right hand side of the equation, we derive law of motion for $\Delta_{t}^{r}$ :

$$
\left[\Delta_{t}^{r}\right]^{\rho}=1+\beta \gamma\left(R_{t+1}\right)^{\sigma \rho}\left\{\left(\frac{W_{t+1}}{W_{t}}\right)^{\rho^{2}(1-\nu) \sigma}\left[\Delta_{t+1}^{r}\right]^{\rho}\right\}
$$

Now substitute the value of $W_{t} \theta l_{t}^{r j k}$ from (19) into the budget constraint of the retiree:

$$
A_{t}^{r j k}+\frac{H_{t+1}^{r j k}}{\frac{R_{t+1}}{\gamma}}=\frac{R_{t} A_{t-1}^{r j k}}{\gamma}+H_{t}^{r j k}-C_{t}^{r j k}
$$

Substituting the guess of $C_{t}^{r j k}$ into the above equation:

$$
A_{t}^{r j k}+\frac{H_{t+1}^{r j k}}{\frac{R_{t+1}}{\gamma}}=\left(1-\xi_{t}\right)\left(\frac{R_{t} A_{t-1}^{r j k}}{\gamma}+H_{t}^{r j k}\right)
$$

Now substitute the guess for $C_{t}^{r j k}$ into the Euler equation for $C_{t}^{r j k}$ and we get: 


$$
\xi_{t+1} \frac{R_{t+1}}{\gamma}\left(A_{t}^{r j k}+\frac{H_{t+1}^{r j k}}{\frac{R_{t+1}}{\gamma}}\right)=\left[\left(\frac{W_{t+1}}{W_{t}}\right)^{\rho(1-v)}\left(\beta R_{t+1}\right)\right]^{\sigma} \xi_{t}\left(\frac{R_{t} A_{t-1}^{r j k}}{\gamma}+H_{t}^{r j k}\right)
$$

Substituting equation(p) into the above equation:

$$
\xi_{t+1} \frac{R_{t+1}}{\gamma}\left(1-\xi_{t}\right)\left(\frac{R_{t} A_{t-1}^{r j k}}{\gamma}+H_{t}^{r j k}\right)=\left[\left(\frac{W_{t+1}}{W_{t}}\right)^{\rho(1-v)}\left(\beta R_{t+1}\right)\right]^{\sigma} \xi_{t}\left(\frac{R_{t} A_{t-1}^{r j k}}{\gamma}+H_{t}^{r j k}\right)
$$

After further simplification,:

$$
\xi_{t}=1-\frac{\xi_{t}}{\xi_{t+1}}\left[\left(\frac{W_{t+1}}{W_{t}}\right)^{\rho \sigma(1-v)} \beta^{\sigma}\left(R_{t+1}\right)^{\sigma-1} \gamma\right]
$$

Comparing equation (s) with (n) and matching coefficients, we get:

$$
\Delta_{t}^{r}=\left(\xi_{t}\right)^{\frac{-1}{\rho}}
$$

Workers Problem

The worker solve the following problem:

$$
\begin{aligned}
& V_{t}^{w j k}\left(A_{t-1}^{w}\right)=\left\{\left[\left(C_{t}^{w j k}\right)^{v}\left(1-l_{t}^{w j k}\right)^{1-v}\right]^{\rho}+\beta\left[\omega V_{t+1}^{w}\left(A_{t}^{w j k}\right)+(1-\omega) V_{t+1}^{r}\left(A_{t}^{w^{r} j k}\right)\right]^{\rho}\right\}^{\frac{1}{\rho}} \\
& \left\{C^{w j k}, l^{w j k}\right\}
\end{aligned}
$$

Subject to:

$$
\begin{gathered}
A_{t}^{w j k}=R_{t} A_{t-1}^{w j k}+W_{t} l_{t}^{w j k}-C_{t}^{w j k} \\
A_{t}^{w^{r} j k}=R_{t} A_{t-1}^{w j k}-C_{t}^{w j k}
\end{gathered}
$$

First order condition with respect $C^{w j k}$ :

$$
\begin{aligned}
& \frac{1}{\rho}\left\{\begin{array}{c}
{\left[\left(C_{t}^{w j k}\right)^{v}\left(1-l_{t}^{w j k}\right)^{1-v}\right]^{\rho}} \\
+\beta\left[\omega V_{t+1}^{w}\left(A_{t}^{w j k}\right)+(1-\omega) V_{t+1}^{r}\left(A_{t}^{w^{r} j k}\right)\right]^{\rho}
\end{array}\right\}^{\frac{1}{\rho}-1} \\
& * \rho\left\{\left[\begin{array}{c}
{\left[\left(C_{t}^{w j k}\right)^{v}\left(1-l_{t}^{w j k}\right)^{1-v}\right]^{\rho-1} v *\left(C_{t}^{w j k}\right)^{v-1}\left(1-l_{t}^{w j k}\right)^{1-v}} \\
+\beta\left[\omega V_{t+1}^{w}\left(A_{t}^{w j k}\right)+(1-\omega) V_{t+1}^{r w}\left(A_{t}^{w^{r} j k}\right)\right]^{\rho-1} \\
{\left[\omega \frac{\partial V_{t+1}^{w}\left(A_{t}^{w j k}\right)}{\partial A_{t}^{w j k}} \frac{\partial A_{t}^{w j k}}{\partial C_{t}^{w j k}}+(1-\omega) \frac{\partial V_{t+1}^{r w}\left(A_{t}^{w^{r} j k}\right)}{\partial A_{t}^{w^{r} j k}} \frac{\partial A_{t}^{w^{r} j k}}{\partial C_{t}^{w j k}}\right]}
\end{array}\right]\right\}=0
\end{aligned}
$$

Envelope conditions:

$$
\begin{aligned}
\frac{\partial V_{t}^{w}}{\partial A_{t-1}^{w}} & \left|\quad C_{t}^{w j k}=C_{t}^{*}\left(A_{t-1}^{w}\right)=\frac{\partial U\left(C_{t}^{w j k}, l_{t}^{w j k}\right)}{\partial A_{t-1}^{w}}\right|_{C_{t}^{w j k}=C_{t}^{*}\left(A_{t-1}^{w}\right)} \\
= & \left(V_{t}^{w}\right)^{1-\rho}\left[\left(C_{t}^{w j k}\right)^{v}\left(1-l_{t}^{w j k}\right)^{1-v}\right]^{\rho-1} v *\left(C_{t}^{w j k}\right)^{v-1}\left(1-l_{t}^{w j k}\right)^{1-v} R_{t}
\end{aligned}
$$


Also because of the risk neutrality assumption, there is another envelope condition which suggests:

$$
\left.\frac{\partial V_{t}^{w}}{\partial A_{t-1}^{w}}\right|_{C_{t}^{w j k}=C_{t}^{*}\left(A_{t-1}^{w}\right)}=\left.\frac{\partial V_{t}^{r}}{\partial A_{t-1}^{r}}\right|_{C_{t}^{r j k}=C_{t}^{*}\left(A_{t-1}^{r}\right)}
$$

Therefore substituting equation(j) and (d) into the first order condition and making some simplification yields the following Euler equation for $C_{t}^{w j k}$ :

$$
\begin{gathered}
\left(C_{t}^{w j k}\right)^{v \rho-1}\left(1-l_{t}^{w j k}\right)^{\rho(1-v)}= \\
\beta R_{t+1}\left[\left[\omega V_{t+1}^{w}\left(A_{t}^{w j k}\right)+(1-\omega) V_{t+1}^{r w}\left(A_{t}^{w^{r} j k}\right)\right]^{\rho-1}\right] \\
{\left[\begin{array}{c}
\omega\left(V_{t+1}^{w}\right)^{1-\rho}\left(C_{t+1}^{w j k}\right)^{v \rho-1}\left(1-l_{t+1}^{w j k}\right)^{(1-v) \rho} \\
+(1-\omega)\left(V_{t+1}^{r}\right)^{1-\rho}\left(C_{t+1}^{r j k}\right)^{v \rho-1}\left(1-l_{t+1}^{r j k}\right)^{(1-v) \rho}
\end{array}\right]}
\end{gathered}
$$

The first order condition with respect to $l_{t}^{w j k}$ yields:

$$
\begin{aligned}
& \frac{1}{\rho}\left\{\begin{array}{c}
{\left[\left(C_{t}^{w j k}\right)^{v}\left(1-l_{t}^{w j k}\right)^{1-v}\right]^{\rho}} \\
+\beta\left[\omega V_{t+1}^{w}\left(A_{t}^{w j k}\right)+(1-\omega) V_{t+1}^{r}\left(A_{t}^{w^{r} j k}\right)\right]^{\rho}
\end{array}\right\}^{\frac{1}{\rho}-1} \\
& * \rho\left\{\left[\begin{array}{c}
{\left[\left(C_{t}^{w j k}\right)^{v}\left(1-l_{t}^{w j k}\right)^{1-v}\right]^{\rho-1}(1-v)\left(C_{t}^{w j k}\right)^{v}\left(1-l_{t}^{w j k}\right)^{-v}} \\
+\beta\left[\omega V_{t+1}^{w}\left(A_{t}^{w j k}\right)+(1-\omega) V_{t+1}^{r w}\left(A_{t}^{w^{r} j k}\right)\right]^{\rho-1} \\
{\left[\omega \frac{\partial V_{t+1}^{w}\left(A_{t}^{w j k}\right)}{\partial A_{t}^{w j k}} \frac{\partial A_{t}^{w j k}}{\partial l_{t}^{w j k}}+(1-\omega) \frac{\partial V_{t+1}^{r w}\left(A_{t}^{w^{r} j k}\right)}{\partial A_{t}^{w^{r} j k}} \frac{\partial A_{t}^{w^{r} j k}}{\partial l_{t}^{w j k}}\right.}
\end{array}\right]\right\}=0
\end{aligned}
$$

Applying same kind of envelope theorem argument as we did for the retiree's problem, we can get:

$$
l_{t}^{w j k}=1-\frac{\mu}{W_{t}} C_{t}^{w j k}
$$

Now guess:

$$
\begin{gathered}
C_{t}^{w j k}=\pi_{t}\left(R_{t} A_{t-1}^{w j k}+H_{t}^{w j k}\right) \\
C_{t}^{w^{r} j k}=\xi_{t}\left(R_{t} A_{t-1}^{w j k}\right)
\end{gathered}
$$

Also guess that $v_{t}^{w}$ has similar form as $v_{t}^{r}$ :

$$
V_{t}^{w j k}=\Delta_{t}^{w} C_{t}^{w j k}\left(\frac{\mu}{W_{t}}\right)^{1-v}
$$

Finally, also guess that $\Delta_{t}^{w}$ has similar form as $\Delta_{t}^{r}$

$$
\Delta_{t}^{w}=\left(\pi_{t}\right)^{\frac{-1}{\rho}}
$$

Substituting first order condition for $l_{t}^{w j k}$ into the Euler equation for $C_{t}^{w j k}$ (equation aa): 


$$
\begin{gathered}
\left(C_{t}^{w j k}\right)^{v \rho-1}\left(\frac{\mu}{W_{t}} C_{t}^{w j k}\right)^{\rho(1-v)}= \\
\beta R_{t+1}\left[\left[\omega V_{t+1}^{w}\left(A_{t}^{w j k}\right)+(1-\omega) V_{t+1}^{r w}\left(A_{t}^{w^{r} j k}\right)\right]^{\rho-1}\right] \\
{\left[\begin{array}{c}
\omega\left(V_{t+1}^{w}\right)^{1-\rho}\left(C_{t+1}^{w j k}\right)^{v \rho-1}\left(\frac{\mu}{W_{t}} C_{t+1}^{w j k}\right)^{(1-v) \rho} \\
+(1-\omega)\left(V_{t+1}^{r}\right)^{1-\rho}\left(C_{t+1}^{w^{r} j k}\right)^{v \rho-1}\left(\frac{\mu}{W_{t}} C_{t+1}^{w^{r} j k}\right)^{(1-v) \rho}
\end{array}\right]}
\end{gathered}
$$

Substituting the guess for $v_{t}^{w}$ and $v_{t}^{r}$ into the above equation and simplifying:

$$
\begin{gathered}
\left(C_{t}^{w j k}\right)^{\rho-1}= \\
\beta R_{t+1}\left(\frac{W_{t}}{W_{t+1}}\right)^{(1-v) \rho}\left[\left[\omega \Delta_{t+1}^{w} C_{t+1}^{w j k}+(1-\omega) \Delta_{t+1}^{r} C_{t+1}^{w^{r} j k} \chi\right]^{\rho-1}\right] \\
{\left[\omega\left(\Delta_{t+1}^{w}\right)^{1-\rho}+(1-\omega)\left(\Delta_{t+1}^{r}\right)^{1-\rho} \chi\right]}
\end{gathered}
$$

Where $\chi$ is defined in (32). Substituting the value of $\Delta_{t}^{w}$ and $\Delta_{t}^{r}$ from our guess into the above equation and simplifying:

$$
\begin{gathered}
{\left[\omega C_{t+1}^{w j k}+(1-\omega) \chi\left(\epsilon_{t+1}\right)^{\frac{\sigma}{1-\sigma}} C_{t+1}^{w^{r} j k}\right]=} \\
\left\{\beta R_{t+1}\left(\frac{W_{t}}{W_{t+1}}\right)^{(1-v) \rho}\left[\omega+(1-\omega)\left(\epsilon_{t+1}\right)^{\frac{1}{1-\sigma}}\right]\right\} C_{t}^{w j k}
\end{gathered}
$$

Now substitute the guess for $C_{t+1}^{w j k}$ and the value of $W_{t} l_{t}^{w j k}$ from (27) into the worker's first budget constraint:

$$
A_{t}^{w j k}+\frac{H_{t+1}^{w j k}}{\frac{\Omega_{t+1} R_{t+1}}{\omega}}=\left(1-\pi_{t}\right)\left(R_{t} A_{t-1}^{w j k}+H_{t}^{w j k}\right)
$$

where $\Omega_{t+1}$ is defined in (27).

Also substitute the guess of $C_{t+1}^{w j k}$ and $C_{t+1}^{w^{r} j k}$ into the Euler equation of (ai) and simplifying we get:

$$
\pi_{t}=1-\left(\frac{W_{t}}{W_{t+1}}\right)^{(1-v) \rho \sigma}\left(R_{t+1} \Omega_{t+1}\right)^{\sigma-1} \frac{\pi_{t}}{\pi_{t+1}}
$$

This is the law of motion for the MPC of the worker.

Thus we have solved the entire system

\section{Appendix 2: Derivation of the Private Annuity Model with scaled variable}

Defining $\tilde{Z}_{t}=\frac{Z_{t}}{X_{t} N_{t}^{w}}$, our system in terms of the scaled variables look like

$$
\begin{gathered}
\tilde{Y}_{t}=\left(\tilde{L_{t}}\right)^{\alpha}\left(\tilde{K_{t-1}}\right)^{1-\alpha}\left(\frac{X_{t} N_{t}^{w}}{X_{t-1} N_{t-1}^{w}}\right)^{\alpha-1} \\
\tilde{C_{t}^{w}}=\pi_{t}\left[\frac{R_{t}\left(1-\lambda_{t-1}\right) \tilde{K}_{t-1}}{\frac{X_{t} N_{t}^{w}}{X_{t-1} N_{t-1}^{w}}}+\tilde{H_{t}^{w}}\right]
\end{gathered}
$$




$$
\begin{aligned}
& \tilde{C}_{t}^{r}=\xi_{t}\left[\frac{R_{t} \lambda_{t-1} \tilde{K_{t-1}}}{\frac{X_{t} N_{t}^{w}}{X_{t-1} N_{t-1}^{w}}}+\tilde{H}_{t}^{r}\right] \\
& \tilde{L_{t}^{w}}=1-\frac{\mu}{\tilde{W}_{t}} \tilde{C_{t}^{w}} \\
& \tilde{L}_{t}=\left(1+\theta \psi_{t}\right)-\frac{\mu}{\tilde{W}_{t}}\left(\tilde{C_{t}^{w}}+\tilde{C}_{t}^{r}\right) \\
& \tilde{H}_{t}^{w}=\tilde{W}_{t} \tilde{L_{t}^{w}}+\frac{\omega \tilde{H_{t+1}^{w}}\left(\frac{X_{t+1} N_{t+1}^{w}}{X_{t} N_{t}^{w}}\right)}{\left(1+n_{t+1}\right) \Omega_{t+1} R_{t+1}} \\
& +\frac{(1-\omega) \tilde{H_{t+1}^{r}}\left(\frac{X_{t+1} N_{t+1}^{w}}{X_{t} N_{t}^{w}}\right)}{\left(1+n_{t+1}\right) \Omega_{t+1} R_{t+1} \psi_{t+1}} \\
& \tilde{H}_{t}^{r}=\theta \tilde{W}_{t}\left(\tilde{L_{t}}-\tilde{L_{t}^{w}}\right)+\frac{\gamma \tilde{H_{t+1}^{r}} \psi_{t}\left(\frac{X_{t+1} N_{t+1}^{w}}{X_{t} N_{t}^{w}}\right)}{R_{t+1} \psi_{t+1}} \\
& \tilde{W}_{t}=\alpha \frac{\tilde{Y}_{t}}{\tilde{L}_{t}} \\
& R_{t+1}=(1-\alpha)\left(\frac{X_{t+1} N_{t+1}^{w}}{X_{t} N_{t}^{w}}\right)^{\alpha}\left(\tilde{L_{t+1}}\right)^{\alpha}\left(\tilde{K}_{t}\right)^{-\alpha}+(1-\delta) \\
& \tilde{K}_{t}=\tilde{Y}_{t}-\tilde{C_{t}^{w}}-\tilde{C_{t}^{r}}+\frac{(1-\delta) \tilde{K_{t-1}}}{\left(\frac{X_{t} N_{t}^{w}}{X_{t-1} N_{t-1}^{w}}\right)} \\
& \tilde{K}_{t}\left(\frac{\lambda_{t}}{\omega}-\frac{1-\omega}{\omega}\right)=\frac{R_{t} \lambda_{t-1} \tilde{K_{t-1}}}{\left(\frac{X_{t} N_{t}^{w}}{X_{t-1} N_{t-1}^{w}}\right)}+W_{t}\left(\tilde{L_{t}}-\tilde{L_{t}^{w}}\right)-\tilde{C}_{t}^{r} \\
& \pi_{t}=1-\left(\frac{\tilde{W_{t}}}{\widetilde{W_{t+1}}}\right)^{(1-v) \rho \sigma}\left(\frac{X_{t+1}}{X_{t}}\right)^{(v-1) \rho \sigma}\left(R_{t+1} \Omega_{t+1}\right)^{\sigma-1} \frac{\pi_{t}}{\pi_{t+1}} \\
& \xi_{t}=1-\left(\frac{\tilde{W_{t}}}{\tilde{W_{t+1}}}\right)^{(1-v) \rho \sigma}\left(\frac{X_{t+1}}{X_{t}}\right)^{(v-1) \rho \sigma} \beta^{\sigma} R_{t+1}^{\sigma-1} \gamma_{t+1} \frac{\xi_{t}}{\xi_{t+1}}
\end{aligned}
$$

The rest of the equations of the system are repeated below

$$
\begin{gathered}
\ln n_{t+1}=\rho_{n} \ln n_{t}+e_{1 t+1}, 0<\rho_{n}<1 \\
\ln X_{t+1}=\rho_{x} \ln X_{t}+e_{1 t+1}, 0<\rho_{x}<1 \\
\psi_{t+1}\left(1+n_{t+1}\right)=\gamma \psi_{t}+(1-\omega)
\end{gathered}
$$




$$
\begin{gathered}
N_{t+1}^{w}=\left(1+n_{t+1}\right) N_{t}^{w} \\
\Omega_{t+1}=\omega+(1-\omega) \chi \epsilon_{t+1}^{\frac{1}{1-\sigma}}
\end{gathered}
$$

Equations (a-r)contain the entire dynamics of the system and therefore will be used to solve model.

Appendix 3: Steady state system of equations of the Private Annuity Model

The steady state system of equations in terms of the scaled variables of the baseline model of appendix 2 can be written as follows

$$
\begin{aligned}
& \widetilde{L}=(1+\theta \psi)-\frac{\mu}{\tilde{W}}\left(\tilde{C}^{w}+\tilde{C}^{r}\right) \\
& \tilde{L}^{w}=1-\frac{\mu}{\tilde{W}} \tilde{C}^{w} \\
& \tilde{C}^{w}=\pi\left[\frac{R(1-\lambda) \tilde{K}}{(1+x+n)}+\tilde{H}^{w}\right] \\
& \tilde{C}^{r}=\xi\left[\frac{R \lambda \tilde{K}}{(1+x+n)}+\tilde{H}^{r}\right] \\
& \pi=1-(1+x)^{(v-1) \rho \sigma}(R \Omega)^{\sigma-1} \\
& \xi=1-(1+x)^{(v-1) \rho \sigma} \beta^{\sigma} R^{\sigma-1} \gamma \\
& \tilde{K}\left(1-\frac{(1-\delta)}{(1+x+n)}\right)=\tilde{Y}-\tilde{C}^{w}-\tilde{C}^{r} \\
& \tilde{K}\left(\frac{\lambda}{\omega}-\frac{1-\omega}{\omega}-\frac{R \lambda}{(1+x+n)}\right)=\tilde{W}\left(\tilde{L}-\tilde{L^{w}}\right)-\tilde{C}^{r} \\
& H^{w}\left(1-\frac{\omega(1+x)}{\Omega R}\right)=\tilde{W} \tilde{L}^{w}+\frac{(1-\omega) \tilde{H}^{r}(1+x)}{(1+n) \Omega R \psi} \\
& \tilde{H}^{r}\left(1-\frac{\gamma(1+x)}{R \psi}\right)=\theta \tilde{W}\left(\tilde{L}-\tilde{L^{w}}\right) \\
& \Omega=\omega+(1-\omega) \chi \epsilon^{\frac{1}{1-\sigma}} \\
& R=(1-\alpha)(1+x+n)^{\alpha}(\tilde{L})^{\alpha}(\tilde{K})^{-\alpha}+(1-\delta) \\
& \tilde{W}=\alpha \frac{\tilde{Y}}{\tilde{L}}
\end{aligned}
$$




$$
\begin{gathered}
\tilde{Y}=(\tilde{L})^{\alpha}(\tilde{K})^{1-\alpha}(1+x+n)^{\alpha-1} \\
\psi=\frac{(1-\omega)}{(1+n-\gamma)}
\end{gathered}
$$

All the other models are solved and scaled and their steady state systems are derived in the similar manner.

Appendix 4: Welfare Calculations under alternative social security Arrangements From the guess of the value function from the Private annuity market, we calculated that

$$
V_{t}^{r}=\Delta_{t}^{r} C_{t}^{r}\left(\frac{\mu}{\theta W_{t}}\right)^{1-v}
$$

Where we can again prove that

$$
\Delta_{t}^{r}=\left(\xi_{t}\right)^{\frac{-1}{\rho}}
$$

Also

$$
V_{t}^{w}=\Delta_{t}^{w} C_{t}^{w}\left(\frac{\mu}{W_{t}}\right)^{1-v}
$$

Where

$$
\Delta_{t}^{w}=\left(\pi_{t}\right)^{\frac{-1}{\rho}}
$$

The guess for the value functions for the PAYGO and the FF systems are similar where the guess about the retiree is same as the private annuity case while the guess for the workers in case of the DC systems look like

$$
V_{t}^{w}=\Delta_{t}^{w} C_{t}^{w}\left(\frac{\mu}{(1-\tau) W_{t}}\right)^{1-v}
$$

Where $\Delta_{t}^{w}$ still satisfies equation(d). In steady state equation (a), (c), (e) in terms of the scaled variables look like

$$
\begin{gathered}
V^{r}=(\xi)^{\frac{-1}{\rho}} \tilde{C}^{r}\left(\frac{\mu}{\theta \tilde{W}}\right)^{1-v} \\
V^{w}=(\pi)^{\frac{-1}{\rho}} \tilde{C^{w}}\left(\frac{\mu}{(1-\tau) \tilde{W}}\right)^{1-v}
\end{gathered}
$$

Now in case of the DB systems, the calculations are as follows:

$$
V_{t}^{w}=\Delta_{t}^{w} C_{t}^{w}\left(\frac{\mu}{\left(1-\tau_{t}\right) W_{t}}\right)^{1-v}
$$

Where $\Delta_{t}^{w}$ still satisfies equation(d). In steady state equation (a), (c), (e) in terms of the scaled variables look like

$$
V^{r}=(\xi)^{\frac{-1}{\rho}} \tilde{C}^{r}\left(\frac{\mu}{\theta \tilde{W}}\right)^{1-v}
$$




$$
V^{w}=(\pi)^{\frac{-1}{\rho}} \tilde{C}^{w}\left(\frac{\mu}{\left(1-\tau_{t}\right) \tilde{W}}\right)^{1-v}
$$

We can therefore take the steady state value of $\tilde{C}^{r}, \tilde{C^{w}}, \xi, \pi, \tilde{W}$ from table-2 along with other exogenous parameter from table- 1 from appendix- 15 and can calculate the indirect utility for the worker and the retiree under alternative systems which again is their welfare. For calculating the aggregate social welfare, we define $V$, the aggregate social welfare as follows

$$
V_{t}=\frac{N_{t}^{w}}{N_{t}} V_{t}^{w}+\frac{N_{t}^{r}}{N_{t}} V_{t}^{r}
$$

Which using equation (6.b) can be written as

$$
\begin{aligned}
& V_{t}=\frac{N_{t}^{w}}{N_{t}^{w}+N_{t}^{r}} V_{t}^{w}+\frac{N_{t}^{r}}{N_{t}^{w}+N_{t}^{r}} V_{t}^{r} \\
& =\frac{1}{1+\frac{N_{t}^{r}}{N_{t}^{w}}} V_{t}^{w}+\frac{}{\frac{N_{t}^{w}}{N_{t}^{r}}+1} V_{t}^{r} \\
& =\frac{1}{1+\frac{1}{\Psi_{t}}} V_{t}^{w}+\frac{1}{\Psi_{t}+1} V_{t}^{r}
\end{aligned}
$$

Where the last inequality uses the definition of $\psi_{t}$. In steady state equation(i) looks like

$$
V=\frac{1}{1+\frac{1}{\Psi}} V^{w}+\frac{1}{\Psi+1} V^{r}
$$

From equation(3), in steady state, the value of $\Psi$ is defined as

$$
\psi=\frac{(1-\omega)}{1+n-\gamma}
$$

We can now calculate the value of $\Psi$ from table1. This will allow us to calculate the aggregate social welfare $V$ once we have calculated the value of $V^{r}$ and $V^{w}$. Finally, it should be noted this since $V_{t}$ is a function of consumption and real wage, which is also measured is terms of consumption units, welfare is also expressed in terms of consumption units. 


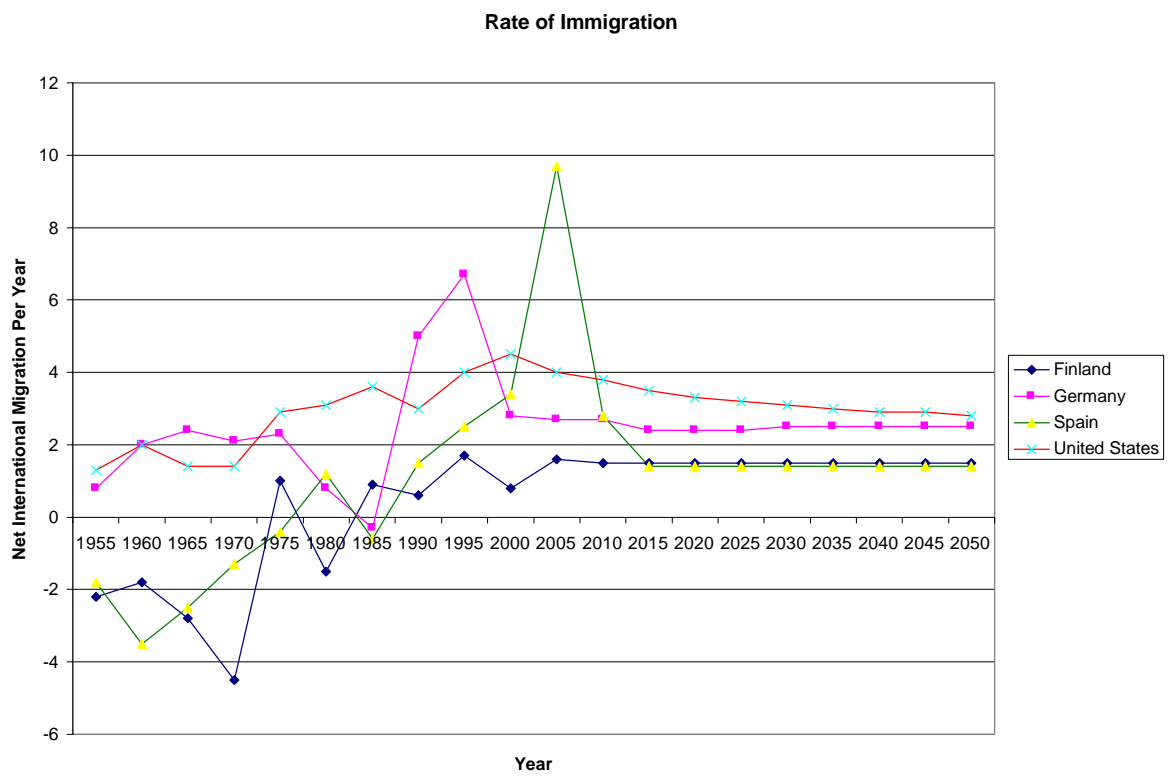

Figure 1: Trends in Immigration: USA and other countries.

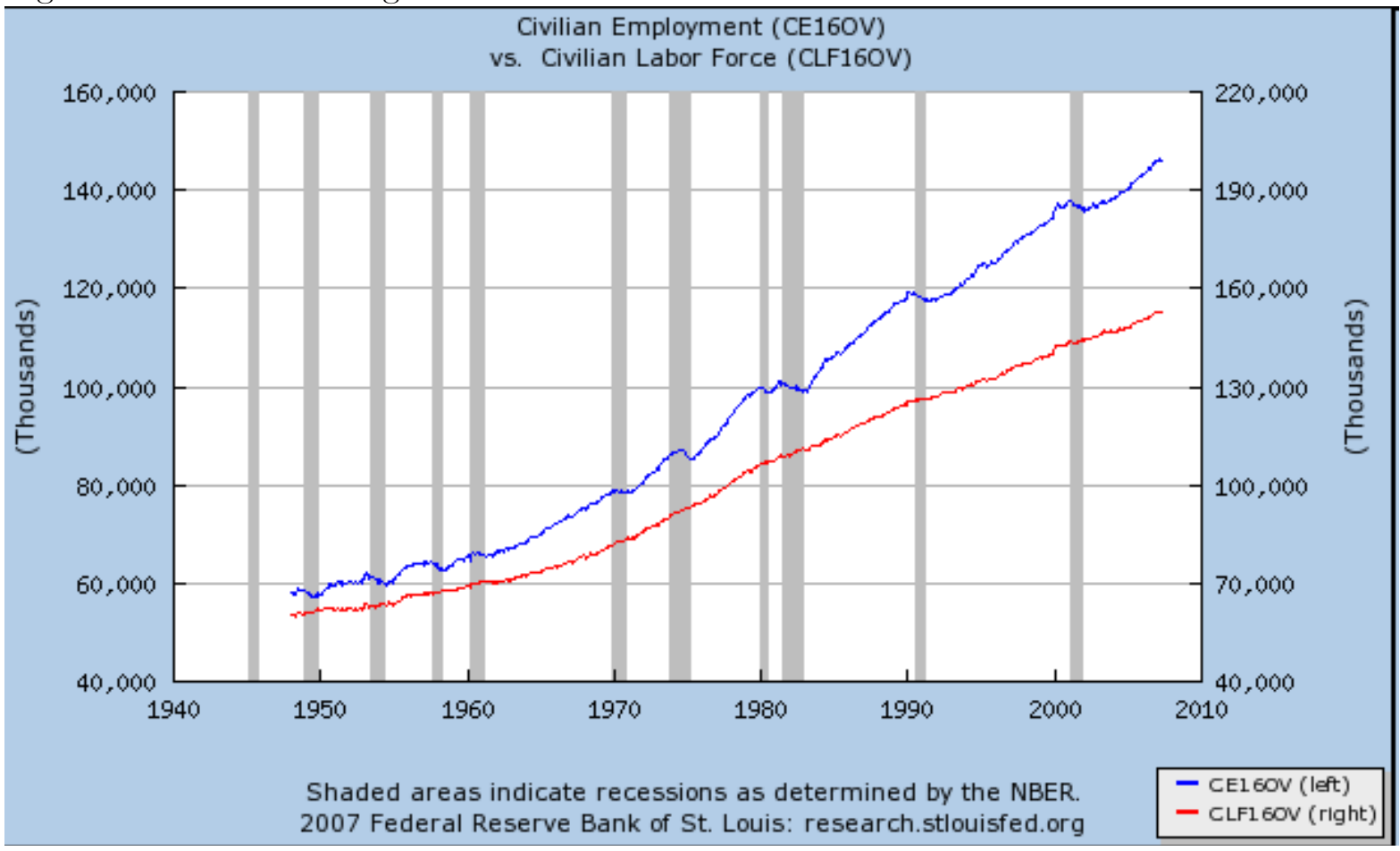

Figure 2: Trends in Civillian employment and labor force. 
Trends in Naturalization of Alliens in USA

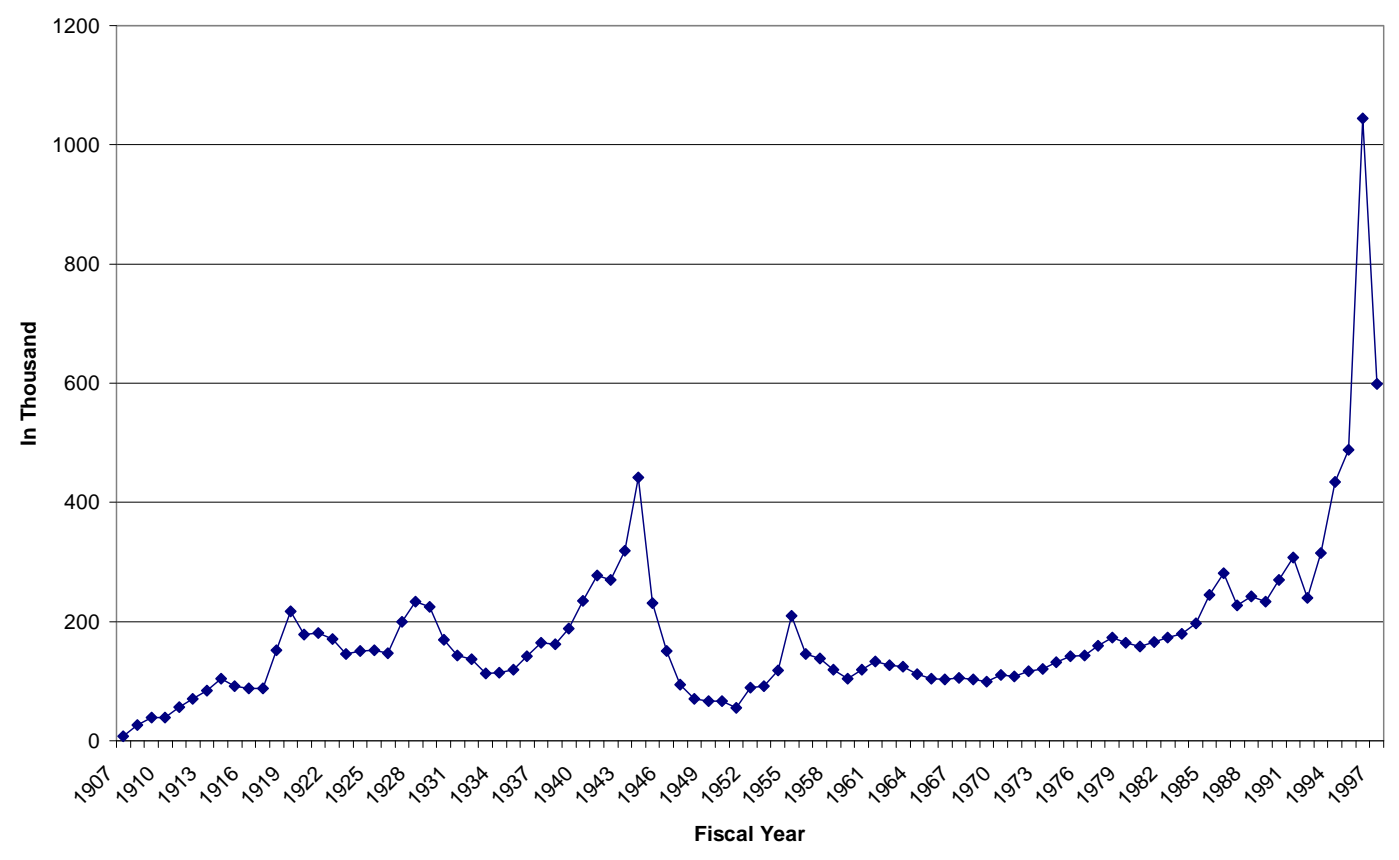

Figure 3: Trends in Naturalization of Aliens in USA. Source: United Nations

Table 3

Labor Force Status, by Year and Gender

Individuals with a Full-Time Career Job in Their Work History and Work Experience Since Age 49

\begin{tabular}{cccccc}
\multicolumn{5}{c}{ Males } \\
& \multicolumn{5}{c}{ Full Time } \\
& $\mathrm{n}$ & Career Job & Bridge Job & $\begin{array}{c}\text { Not in } \\
\text { Labor Force }\end{array}$ & $\begin{array}{c}\text { Don't } \\
\text { Know }\end{array}$ \\
\hline 1992 & 4,695 & $65.9 \%$ & $14.5 \%$ & $19.0 \%$ & $0.7 \%$ \\
1994 & 4,353 & $52.6 \%$ & $18.5 \%$ & $28.3 \%$ & $0.6 \%$ \\
1996 & 4,044 & $42.4 \%$ & $22.2 \%$ & $34.7 \%$ & $0.7 \%$ \\
1998 & 3,833 & $27.0 \%$ & $29.3 \%$ & $42.7 \%$ & $1.0 \%$ \\
2000 & 3,573 & $18.0 \%$ & $33.0 \%$ & $47.7 \%$ & $1.3 \%$ \\
2002 & 3,414 & $14.4 \%$ & $25.3 \%$ & $55.6 \%$ & $4.7 \%$ \\
\hline
\end{tabular}

\begin{tabular}{cccccc}
\multicolumn{5}{c}{ Females } \\
& \multicolumn{5}{c}{ Full Time } \\
& Career Job & Bridge Job & $\begin{array}{c}\text { Not in } \\
\text { Labor Force }\end{array}$ & $\begin{array}{c}\text { Don't } \\
\text { Know }\end{array}$ \\
\hline 1992 & 3,472 & $72.7 \%$ & $14.1 \%$ & $12.7 \%$ & $0.5 \%$ \\
1994 & 3,272 & $62.0 \%$ & $17.4 \%$ & $20.2 \%$ & $0.5 \%$ \\
1996 & 3,102 & $51.4 \%$ & $19.2 \%$ & $28.9 \%$ & $0.5 \%$ \\
1998 & 2,984 & $32.6 \%$ & $29.9 \%$ & $36.3 \%$ & $1.3 \%$ \\
2000 & 2,855 & $19.4 \%$ & $38.3 \%$ & $40.7 \%$ & $1.7 \%$ \\
2002 & 2,795 & $17.4 \%$ & $27.7 \%$ & $49.7 \%$ & $5.2 \%$ \\
\hline
\end{tabular}

Source: Authors' calculations based on the Health and Retirement Study.

Figure 4: Trend in Part Time Jobs for the retirees(Cahill, Giandrea and Quinn(2005)) 
Table 5

First Transitions from Career Jobs by 2002

Those with Full-Time Career Jobs in 1992, by Gender and Age (horizontal percentage and ratio)

\begin{tabular}{ccccccc} 
Age in 2002 & $\mathrm{n}$ & $\begin{array}{c}\text { Still on } \\
\text { Career Job }\end{array}$ & $\begin{array}{c}\text { Moved to } \\
\text { Bridge Job }\end{array}$ & $\begin{array}{c}\text { Moved to } \\
\text { No Job }\end{array}$ & $\begin{array}{c}\text { Don't } \\
\text { Know }\end{array}$ & $\begin{array}{c}\text { Ratio of Bridge Job/ } \\
\text { Bridge Job + No Job) }\end{array}$ \\
\hline $\begin{array}{c}\text { Men } \\
<60\end{array}$ & 92 & $28.5 \%$ & $37.9 \%$ & $22.2 \%$ & $11.4 \%$ & $63.1 \%$ \\
$60-61$ & 461 & $24.7 \%$ & $43.5 \%$ & $24.8 \%$ & $7.1 \%$ & $63.7 \%$ \\
$62-64$ & 819 & $18.6 \%$ & $43.0 \%$ & $30.2 \%$ & $8.3 \%$ & $58.7 \%$ \\
$65+$ & $\underline{1,348}$ & $\underline{9.7 \%}$ & $\underline{37.5 \%}$ & $\underline{47.5 \%}$ & $\underline{5.3 \%}$ & $\underline{44.1 \%}$ \\
Total & 2,720 & $15.5 \%$ & $40.2 \%$ & $37.6 \%$ & $6.7 \%$ & \\
Women & & & & & & \\
$<60$ & 542 & $26.5 \%$ & $52.8 \%$ & $15.0 \%$ & $5.6 \%$ & $77.9 \%$ \\
$60-61$ & 402 & $26.9 \%$ & $39.2 \%$ & $25.6 \%$ & $8.3 \%$ & $60.5 \%$ \\
$62-64$ & 596 & $15.3 \%$ & $46.0 \%$ & $32.4 \%$ & $6.4 \%$ & $58.7 \%$ \\
$65+$ & $\underline{770}$ & $\underline{8.1 \%}$ & $\underline{35.9 \%}$ & $\underline{52.6 \%}$ & $\underline{3.5 \%}$ & $\underline{50.6 \%}$ \\
Total & 2,310 & $17.6 \%$ & $43.1 \%$ & $33.7 \%$ & $5.6 \%$ & $56.1 \%$ \\
\hline
\end{tabular}

Source: Authors' calculations based on the Health and Retirement Study.

Figure 5: Trend in Transition to Part Time Jobs for the retirees(Cahill, Giandrea and Quinn(2005)) 


\begin{tabular}{|l|l|l|l|l|}
\hline & & PAYGO & FF & Private Annuity \\
\hline Parameter & Definition & Value & Value & Value \\
$\theta$ & Skill Coefficient for the Retiree & 0.6 & 0.6 & 0.6 \\
$\beta$ & Discount Factor & 0.96 & 0.958 & 0.96 \\
$\delta$ & Capital Depreciation rate & 0.1 & 0.1 & 0.1 \\
$\sigma$ & Intertemporal elasticity of substitution & 0.25 & 0.25 & 0.25 \\
$\alpha$ & Labor's share in production & 0.667 & 0.667 & 0.667 \\
$\omega$ & Retirement probability & 0.997 & 0.997 & 0.997 \\
$x$ & Steady state growth rate of technology & 0.01 & 0.01 & 0.01 \\
$n$ & Steady state growth rate of population & 0.01 & 0.01 & 0.01 \\
\hline$v$ & Consumption share in the utility & 0.5 & 0.5 & 0.5 \\
\hline$\mu$ & $\frac{1-v}{v}$ & 1.5 & 1.5 & 1.5 \\
\hline$\tau$ & Average social security tax & 0.124 & 0.124 & 0.124 \\
\hline$B$ & Participation rate & 0.2495 & 0.2495 & 0.2495 \\
\hline
\end{tabular}

Table 1: Exogenous Parameters of the Models

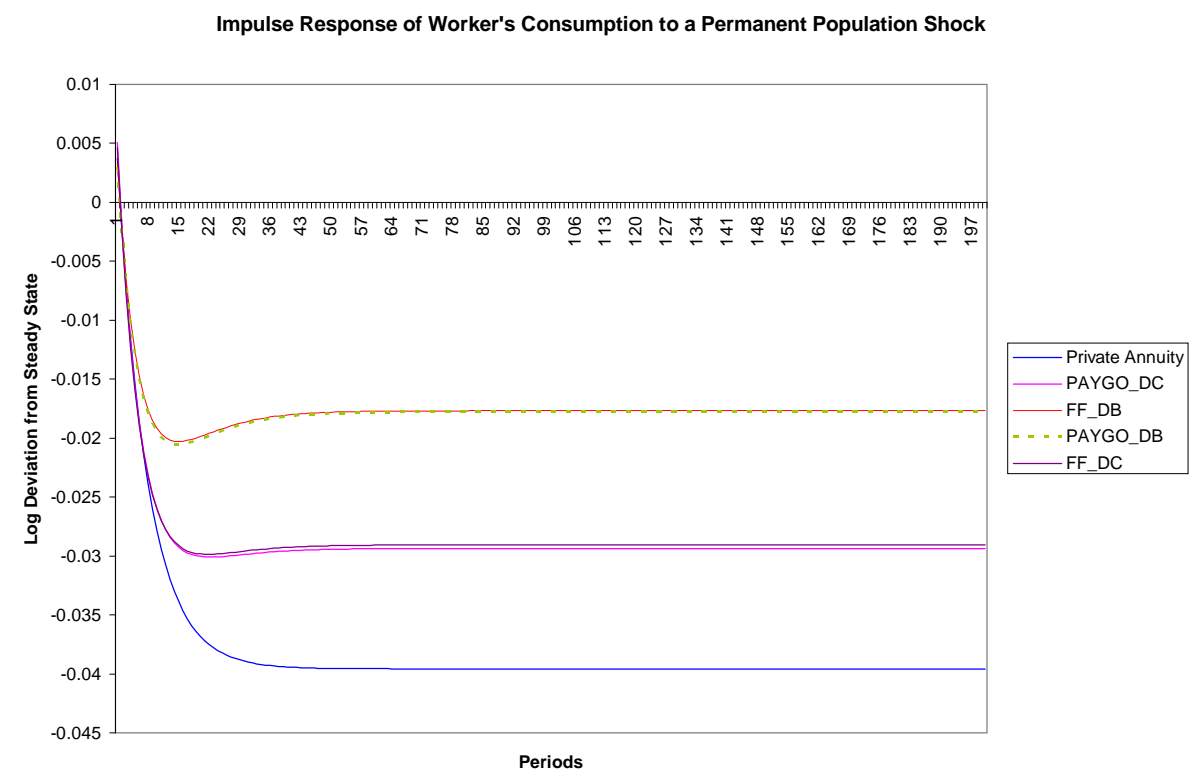

Figure 6: Impulse Response of worker's consumption to a permanent population shock(Log Deviations from the steady state) 


\begin{tabular}{|c|c|c|c|c|c|c|c|c|c|c|}
\hline Scaled & \multicolumn{2}{|c|}{ PrivateAnnuity } & \multicolumn{2}{|c|}{ PAYGO-DB } & \multicolumn{2}{|c|}{ FF-DB } & \multicolumn{2}{|c|}{ PAYGO-DC } & \multicolumn{2}{|c|}{ FF-DC } \\
\hline Variables & Initial & Final & Initial & Final & Initial & Final & Initial & Final & Initial & Final \\
\hline$Y$ & 0.791 & 0.753 & 0.714 & 0.692 & 0.704 & 0.682 & 0.714 & 0.681 & 0.704 & 0.672 \\
\hline$C^{w}$ & 0.434 & 0.417 & 0.369 & 0.363 & 0.367 & 0.361 & 0.369 & 0.358 & 0.367 & 0.357 \\
\hline$C^{r}$ & 0.075 & 0.067 & 0.116 & 0.103 & 0.114 & 0.102 & 0.116 & 0.103 & 0.114 & 0.102 \\
\hline$L$ & 0.460 & 0.456 & 0.437 & 0.437 & 0.434 & 0.435 & 0.437 & 0.433 & 0.434 & 0.431 \\
\hline$L^{w}$ & 0.432 & 0.432 & 0.421 & 0.419 & 0.418 & 0.417 & 0.421 & 0.415 & 0.418 & 0.413 \\
\hline$H^{w}$ & 6.502 & 5.955 & 3.726 & 3.564 & 3.638 & 3.478 & 3.726 & 3.439 & 3.638 & 3.357 \\
\hline$H^{r}$ & 0.306 & 0.324 & 0.156 & 0.263 & 0.155 & 0.258 & 0.156 & 0.255 & 0.155 & 0.251 \\
\hline$K$ & 2.391 & 2.122 & 1.953 & 1.790 & 1.889 & 1.733 & 1.953 & 1.742 & 1.889 & 1.687 \\
\hline$K^{w}$ & 1.994 & 1.811 & 1.7 & 1.213 & 1.643 & 1.167 & 1.70 & 1.101 & 1.643 & 1.054 \\
\hline$K^{r}$ & 0.397 & 0.291 & 0.254 & 0.160 & 0.245 & 0.154 & 0.254 & 0.140 & 0.245 & 0.134 \\
\hline$\lambda$ & 0.166 & 0.137 & 0.130 & 0.089 & 0.130 & 0.089 & 0.130 & 0.080 & 0.130 & 0.080 \\
\hline$W$ & 1.148 & 1.102 & 1.091 & 1.056 & 1.081 & 1.047 & 1.091 & 1.050 & 1.081 & 1.041 \\
\hline$R$ & 1.012 & 1.021 & 1.024 & 1.032 & 1.027 & 1.035 & 1.024 & 1.034 & 1.027 & 1.036 \\
\hline$\pi$ & 0.051 & 0.054 & 0.068 & 0.070 & 0.069 & 0.072 & 0.068 & 0.071 & 0.069 & 0.072 \\
\hline$\varepsilon$ & 0.107 & 0.111 & 0.126 & 0.130 & 0.128 & 0.132 & 0.126 & 0.130 & 0.128 & 0.132 \\
\hline$\psi$ & 0.209 & 0.191 & 0.209 & 0.191 & 0.209 & 0.191 & 0.209 & 0.191 & 0.209 & 0.191 \\
\hline$L^{r}$ & 0.016 & 0.037 & 0.010 & 0.024 & 0.010 & 0.024 & 0.010 & 0.023 & 0.010 & 0.024 \\
\hline TaxRate & & & 0.124 & 0.114 & 0.124 & 0.114 & 0.124 & 0.124 & 0.124 & 0.124 \\
\hline SS Benefit & & & 0.0569 & 0.0503 & 0.0569 & 0.0499 & 0.0569 & 0.05 & 0.0564 & 0.0496 \\
\hline
\end{tabular}

Table 2: Comparison between Initial and Final steady state after a permanent Population shock

\begin{tabular}{|l|l|l|l|l|l|}
\hline Variable & PrivateAnnuity & PAYGO-DB & FF-DB & PAYGO-DC & FF-DC \\
\hline$Y$ & -0.015 & -0.014 & -0.013 & -0.017 & -0.017 \\
\hline$C^{w}$ & 0.004 & 0.003 & 0.003 & 0.005 & 0.005 \\
\hline$C^{r}$ & 0.063 & 0.039 & 0.039 & 0.049 & 0.048 \\
\hline AbsDiff & $\mathbf{0 . 0 6 0}$ & $\mathbf{0 . 0 3 6}$ & $\mathbf{0 . 0 3 5}$ & $\mathbf{0 . 0 4 4}$ & $\mathbf{0 . 0 4 3}$ \\
\hline$L$ & -0.017 & -0.016 & -0.015 & -0.021 & -0.02 \\
\hline$L^{w}$ & -0.002 & 0.001 & 0.001 & -0.002 & -0.002 \\
\hline$H^{w}$ & -0.039 & -0.0019 & -0.019 & -0.034 & -0.034 \\
\hline$H^{r}$ & 0.1040 & 0.336 & 0.329 & 0.265 & 0.257 \\
\hline$K$ & -0.016 & -0.017 & -0.017 & -0.019 & -0.019 \\
\hline$K^{w}$ & -0.015 & -0.04 & -0.044 & -0.047 & -0.045 \\
\hline$K^{r}$ & -0.044 & -0.064 & -0.067 & -0.074 & -0.071 \\
\hline$\lambda$ & -0.028 & -0.047 & -0.05 & -0.055 & -0.052 \\
\hline$W$ & 0.002 & 0.002 & 0.002 & 0.004 & 0.004 \\
\hline$R$ & -0.001 & 0.0 & 0.0 & -0.001 & -0.001 \\
\hline$\pi$ & 0.036 & 0.033 & 0.033 & 0.038 & 0.038 \\
\hline$\varepsilon$ & 0.024 & 0.024 & 0.024 & 0.026 & 0.026 \\
\hline$\psi$ & -0.10 & -0.010 & -0.010 & -0.01 & -0.010 \\
\hline$L^{r}$ & -0.266 & -0.010 & -0.010 & -0.01 & -0.010 \\
\hline$S^{w}$ & & -0.071 & -0.071 & -0.034 & -0.035 \\
\hline$S^{r}$ & & -6.349 & -6.169 & -2.925 & -2.839 \\
\hline Tax Rate & & -0.010 & -0.018 & & \\
\hline Benefit Rate & & & & 0.008 & -0.004 \\
\hline Total Benefit(TB) & & -0.008 & -0.008 & -0.006 & -0.006 \\
\hline
\end{tabular}

Table 3: Immediate response of a permanent population shock under alternative social security arrangements(Log-deviations from the steady state). 


\begin{tabular}{|l|l|l|l|l|l|l|}
\hline Social Security Systems & \multicolumn{4}{|l|}{ Initial Steady State } & \multicolumn{3}{l|}{ Final Steady State } \\
\hline & $V^{w}$ & $V^{r}$ & $V$ & $V^{w}$ & $V^{r}$ & $V$ \\
Private Annuity & 0.026 & 0.013 & 0.024 & 0.027 & 0.012 & 0.025 \\
PAYGO-DC & 0.033 & 0.024 & 0.031 & 0.034 & 0.022 & 0.032 \\
FF-DC & 0.034 & 0.024 & 0.032 & 0.035 & 0.023 & 0.033 \\
PAYGO-DB & 0.033 & 0.024 & 0.031 & 0.034 & 0.022 & 0.032 \\
FF-DB & 0.034 & 0.024 & 0.032 & 0.035 & 0.023 & 0.033 \\
\hline
\end{tabular}

Table 4: Welfare calculations before and after a permanent population $\operatorname{shock}(\tau=0.124)$

\begin{tabular}{|l|l|l|l|l|l|}
\hline Scaled & PrivateAnnuity & PAYGO-DC & FF-DB & PAYGO-DB & FF-DC \\
\hline Variables & (Periods) & (Periods) & (Periods) & (Periods) & (Periods) \\
\hline$Y$ & 87 & 44 & 63 & 64 & 45 \\
\hline$C^{w}$ & 55 & 75 & 80 & 71 & 80 \\
\hline$C^{r}$ & 89 & 71 & 59 & 60 & 74 \\
\hline$L$ & 65 & 53 & 64 & 56 & 55 \\
\hline$L^{w}$ & 52 & 74 & 60 & 60 & 71 \\
\hline$H^{w}$ & 51 & 61 & 63 & 71 & 47 \\
\hline$H^{r}$ & 86 & 87 & 67 & 73 & 70 \\
\hline$K$ & 53 & 60 & 59 & 74 & 50 \\
\hline$\lambda$ & 72 & 91 & 84 & 92 & 95 \\
\hline$W$ & 49 & 61 & 55 & 48 & 76 \\
$R$ & 33 & 52 & 41 & 34 & 24 \\
$\pi$ & 44 & 58 & 72 & 59 & 58 \\
$\varepsilon$ & 38 & 37 & 45 & 43 & 43 \\
$\psi$ & 73 & 73 & 73 & 73 & 73 \\
$L^{r}$ & 85 & 70 & 83 & 75 & 81 \\
\hline
\end{tabular}

Table 5: Speed of convergence after a permanent population shock under alternative social security systems

\begin{tabular}{|l|l|l|l|l|l|}
\hline Scaled & PrivateAnnuity & PAYGO-DB & FF-DB & PAYGO-DC & FF-DC \\
\hline Variables & (Periods) & (Periods) & (Periods) & (Periods) & (Periods) \\
\hline$S T D(Y)$ & 5.99 & 2.88 & 2.67 & 2.95 & 2.73 \\
\hline$S T D\left(C^{w}\right)$ & 4.91 & 2.36 & 2.21 & 2.44 & 2.28 \\
\hline$S T D\left(C^{r}\right)$ & 4.16 & 2.02 & 1.91 & 2.09 & 1.98 \\
\hline$S T D(K)$ & 2.51 & 1.33 & 1.29 & 1.37 & 1.32 \\
\hline$S T D(W)$ & 2.24 & 1.24 & 1.20 & 1.26 & 1.23 \\
\hline$S T D(R)$ & 2.15 & 1.21 & 1.17 & 1.23 & 1.20 \\
\hline$S T D\left(\frac{C^{w}}{C^{r}}\right)$ & 1.18 & 1.17 & 1.16 & 1.17 & 1.16 \\
\hline$S T D\left(\frac{C^{w}}{Y}\right)$ & 0.82 & 0.82 & 0.83 & 0.83 & 0.84 \\
\hline$S T D\left(\frac{C^{\prime}}{Y}\right)$ & 0.69 & 0.70 & 0.71 & 0.71 & 0.72 \\
\hline$S T D\left(\frac{K}{Y}\right)$ & 0.42 & 0.46 & 0.48 & 0.46 & 0.78 \\
\hline
\end{tabular}

Table 6: Comparison of Volatility under alternative social security systems(Standard deviation of the scaled variables) 


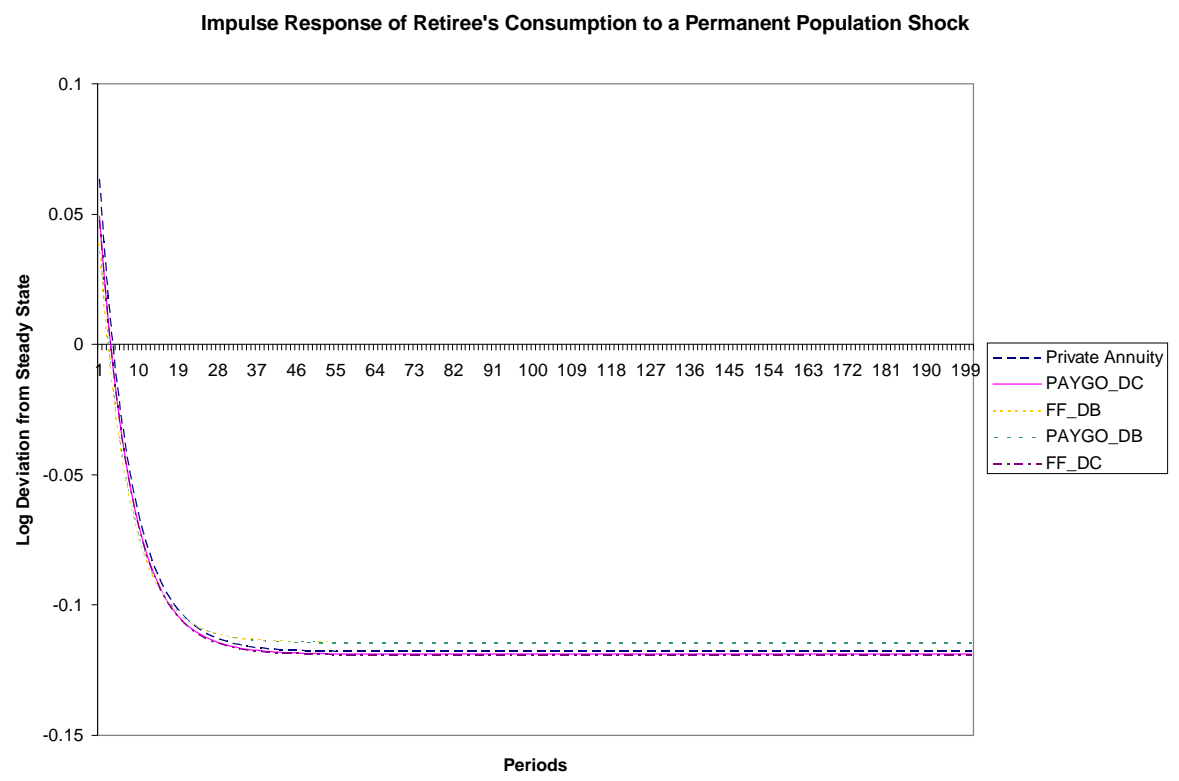

Figure 7: Impulse Response of retiree's consumption to a permanent population shock(Log Deviations from the steady state)

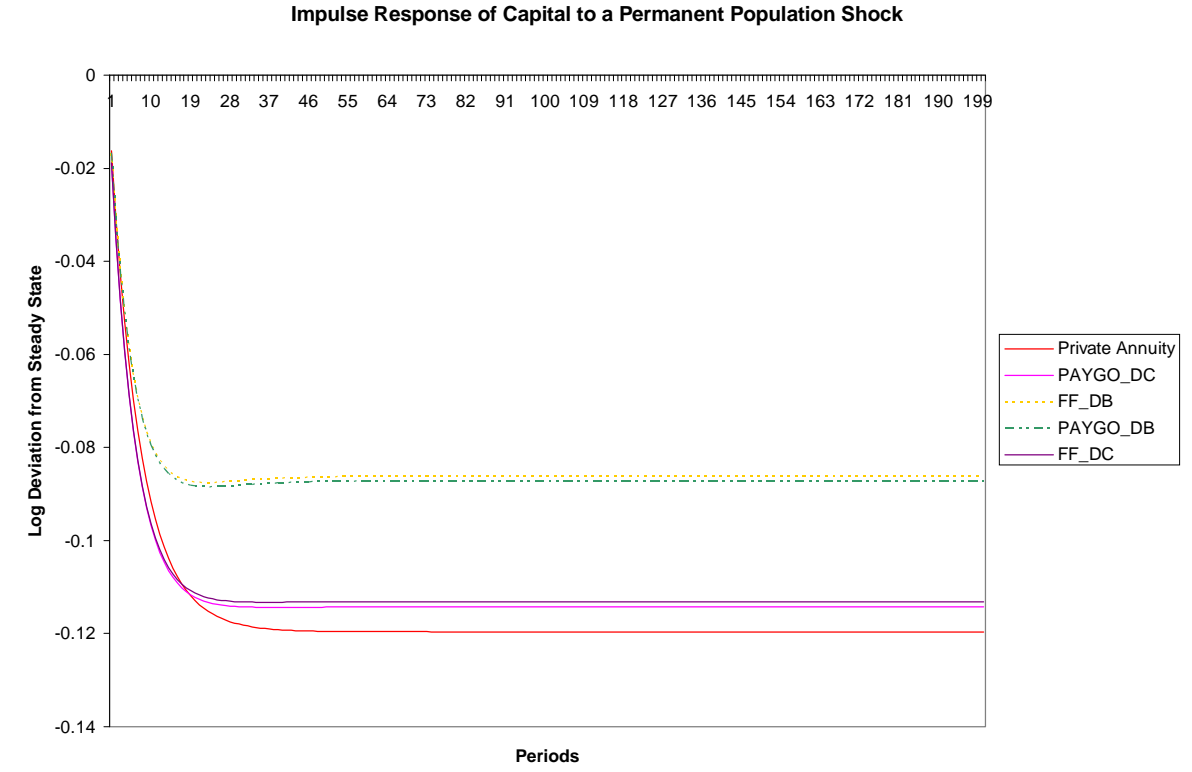

Figure 8: Impulse Response of capital to a permanent population shock(Log Deviations from the steady state) 


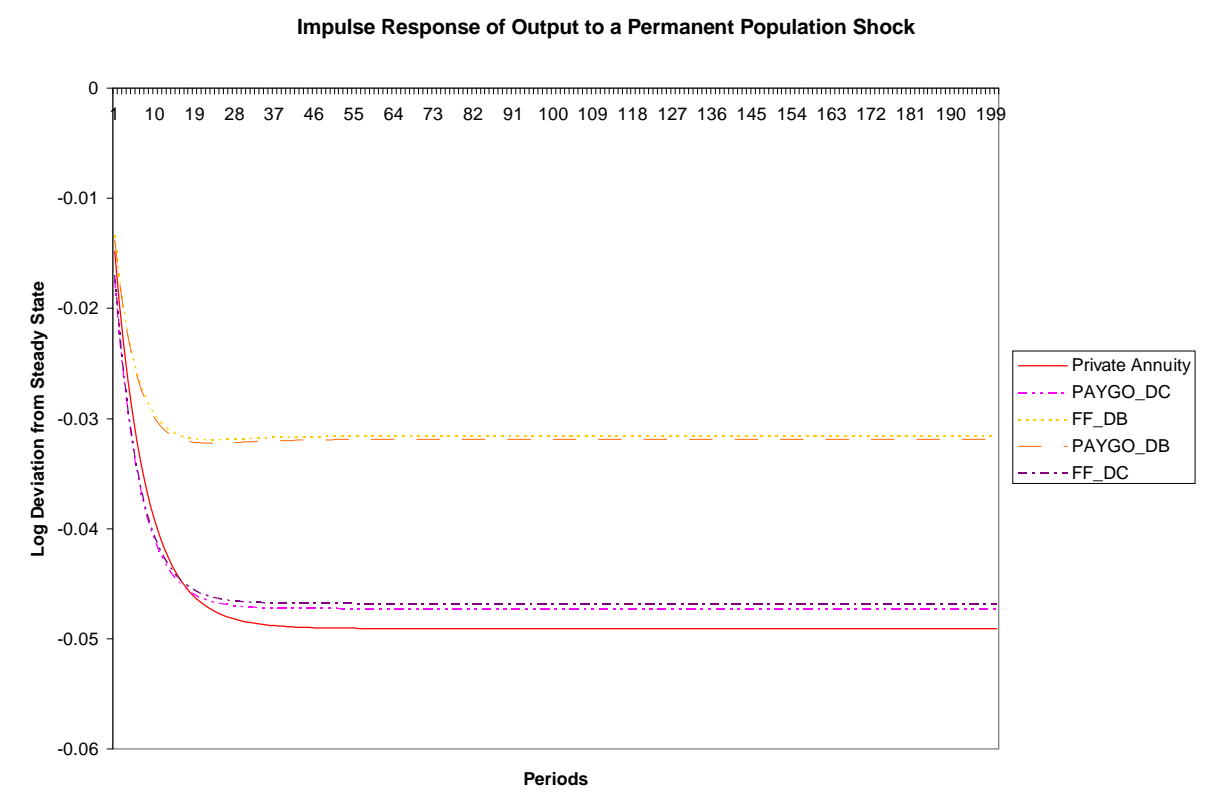

Figure 9: Impulse Response of output to a permanent population shock(Log Deviations from the steady state)

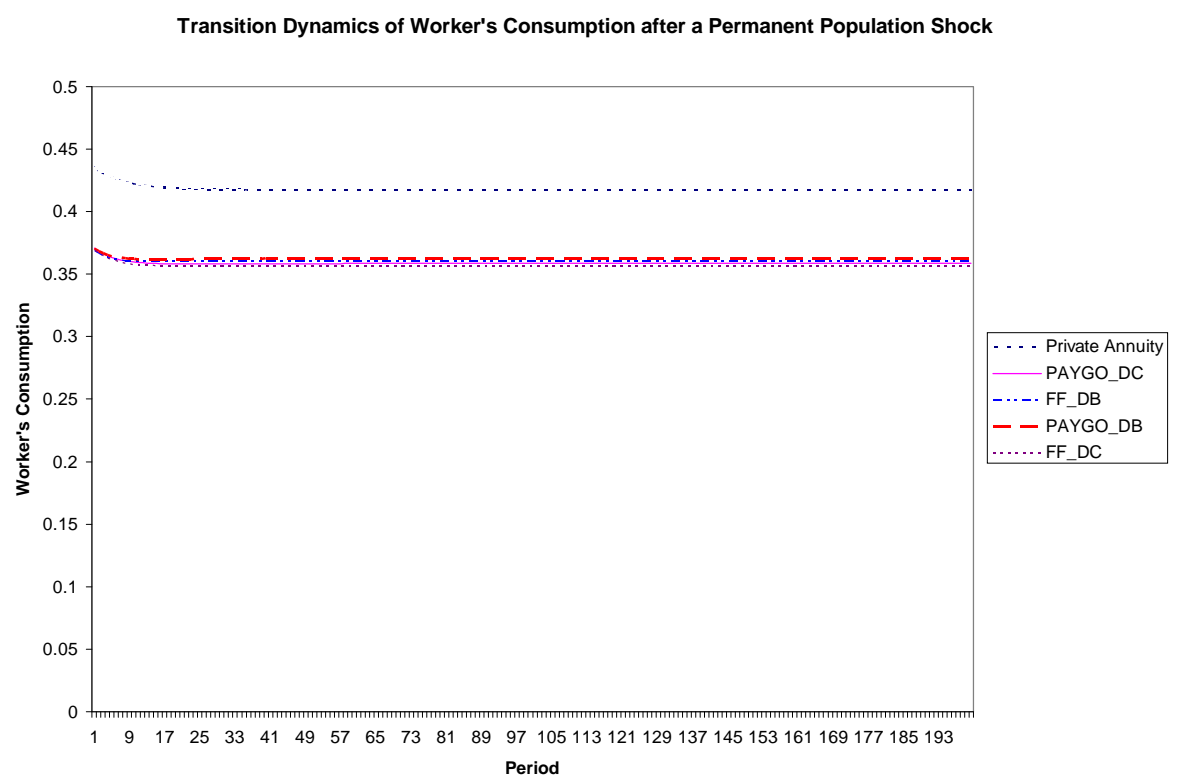

Figure 10: Transitional dynamics of worker's consumption to a permanent population shock(in levels) 


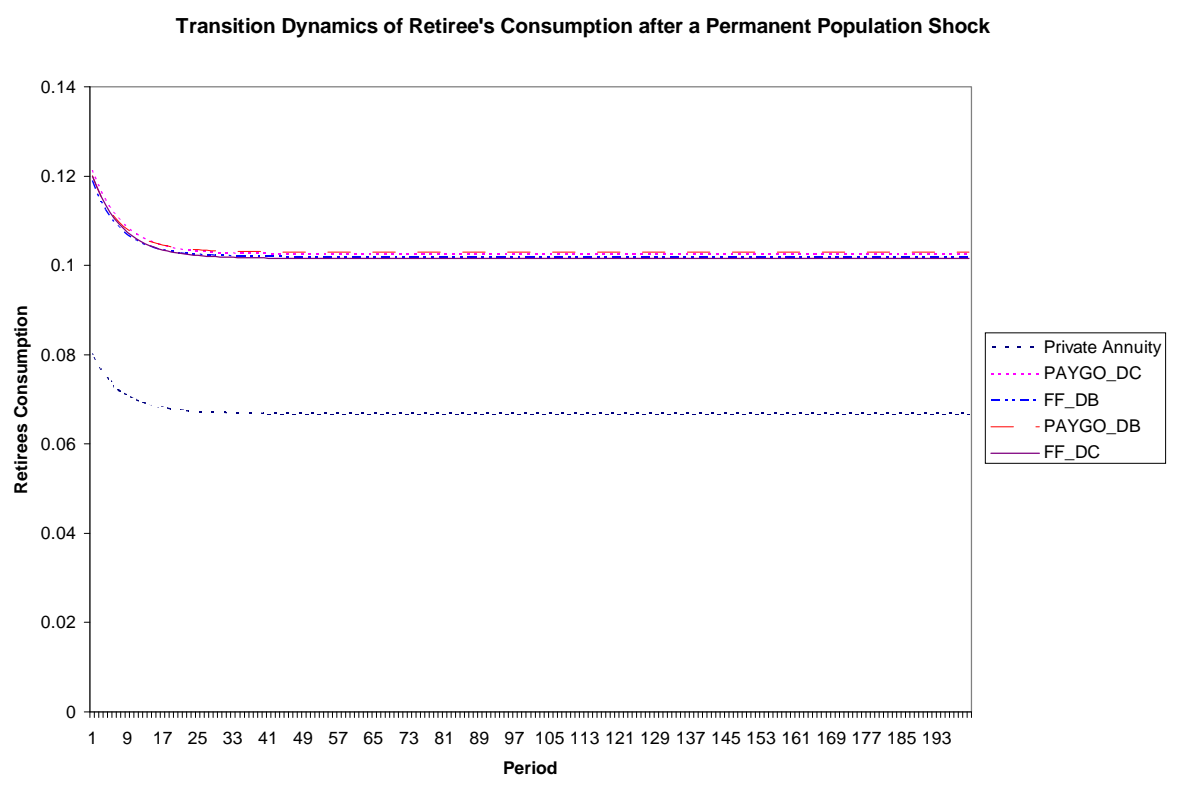

Figure 11: Transitional dynamics of retiree's consumption to a permanent population shock(in levels)

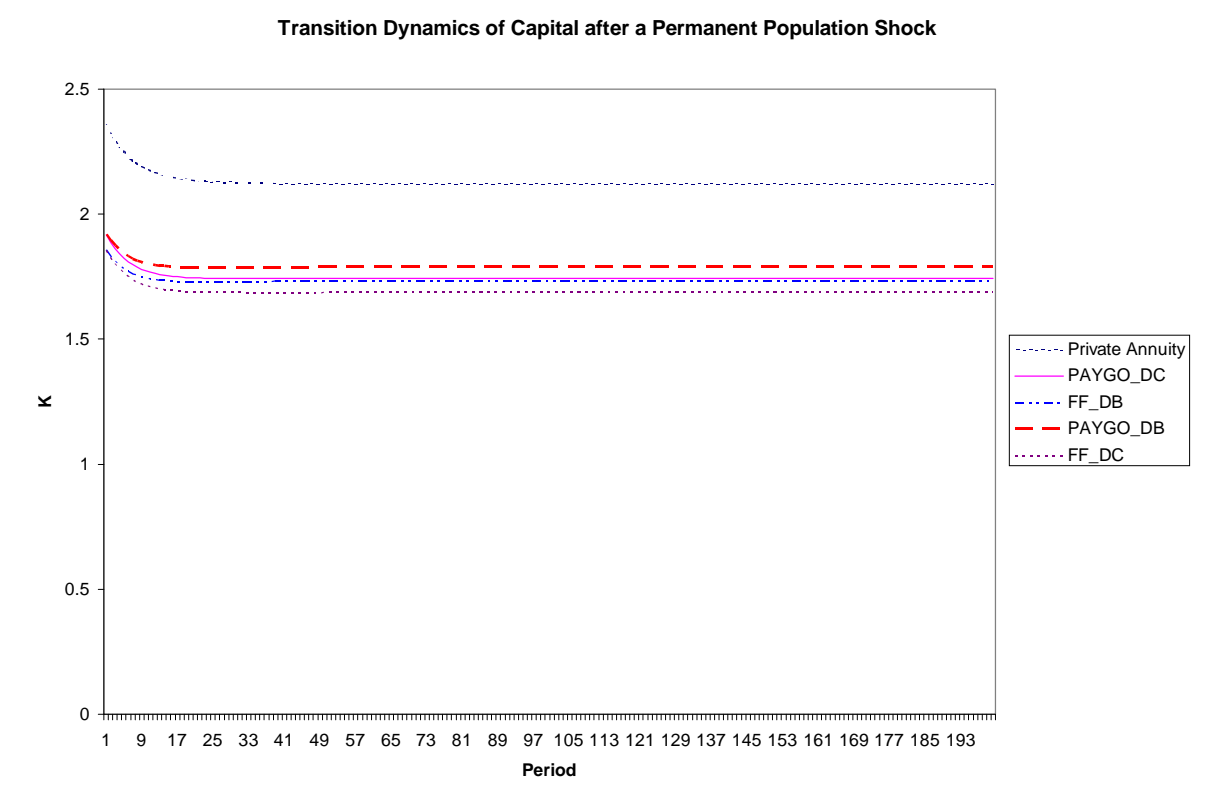

Figure 12: Transitional dynamics of capital to a permanent population shock(in levels) 


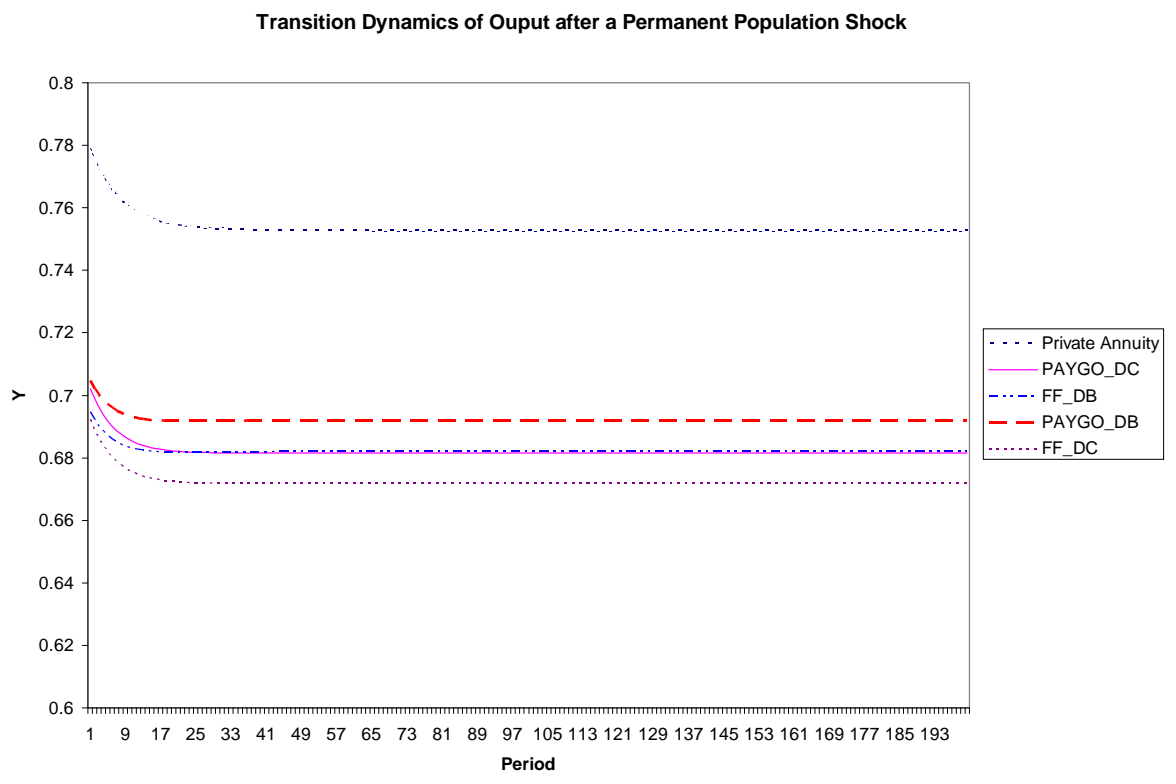

Figure 13: Transitional dynamics of output to a permanent population shock(in levels)

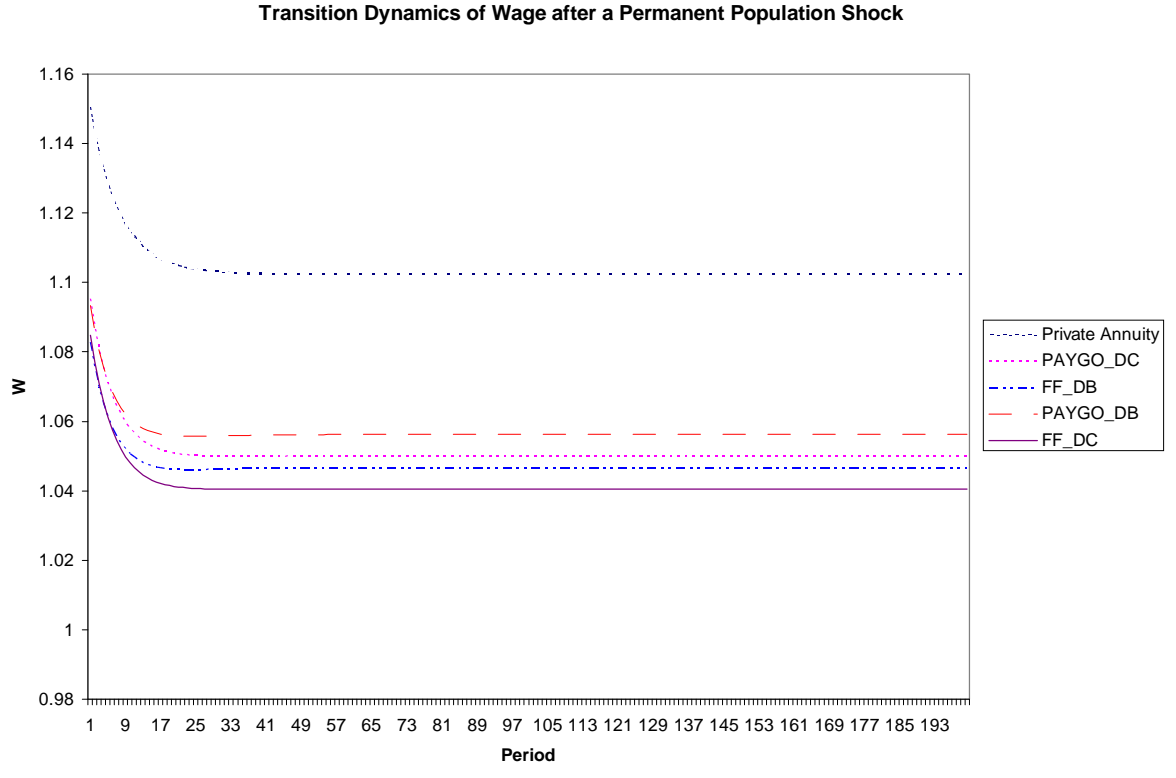

Figure 14: Transitional dynamics of wage to a permanent population shock(in levels) 


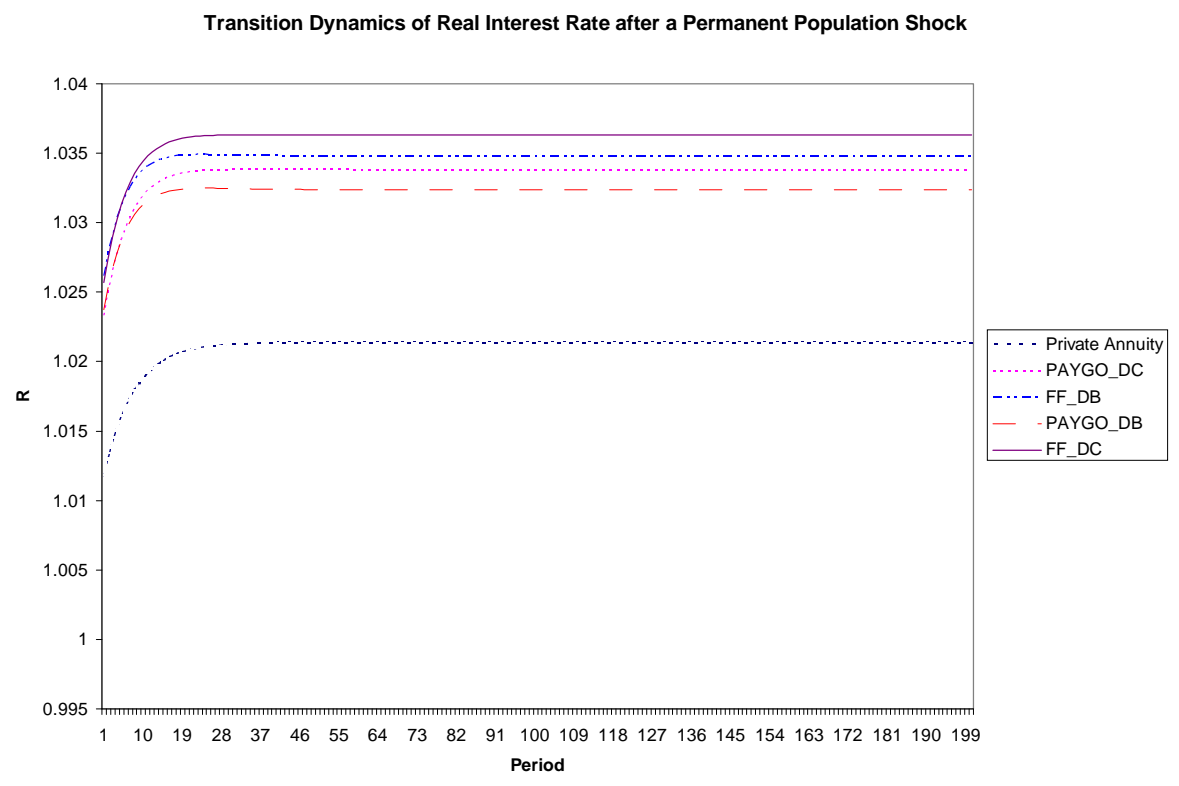

Figure 15: Transitional dynamics of real interest rate to a permanent population shock(in levels) 